University of Wollongong

Research Online

Australian Institute for Innovative Materials -

Papers

Australian Institute for Innovative Materials

$1-1-2019$

\title{
Nitrogen/sulfur dual-doping of reduced graphene oxide harvesting hollow ZnSnS3 nano-microcubes with superior sodium storage
}

Xiaojing Liu

Tianjin Normal University

Youchen Hao

Xi'an University of Technology

Jie Shu

Ningbo University

Hirbod Maleki Kheimeh Sari

Xi'an University of Technology

Liangxu Lin

University of Wollongong, liangxu@uow.edu.au

See next page for additional authors

Follow this and additional works at: https://ro.uow.edu.au/aiimpapers

Part of the Engineering Commons, and the Physical Sciences and Mathematics Commons

Research Online is the open access institutional repository for the University of Wollongong. For further information contact the UOW Library: research-pubs@uow.edu.au 


\title{
Nitrogen/sulfur dual-doping of reduced graphene oxide harvesting hollow ZnSnS3 nano-microcubes with superior sodium storage
}

\author{
Abstract \\ Bimetallic sulfides have exhibited promising applications in advanced sodium-ion batteries (SIBs) due to \\ their relatively high electronic conductivity and electrochemical activity. In this study, for the first time, the \\ $\mathrm{N} / \mathrm{S}$ dual-doped reduced graphene oxide (rGO) encapsulating hollow ZnSnS3 nano-microcubes (N/S- \\ rGO@ZnSnS3) is designed to improve the sluggish reaction kinetics, poor cycling stability and \\ unsatisfactory rate capability of metal sulfides. To examine this design, the cycling stability and rate \\ capability of the desired anode material is studied in detail. It is found that N/S-rGO@ZnSnS3 hybrid \\ delivers a high discharge capacity of $501.7 \mathrm{mAh} \mathrm{g-1}$ after 100 cycles at $0.1 \mathrm{~A} \mathrm{~g}-1$, and a reversible \\ capacity of $290.7 \mathrm{mAh} \mathrm{g}-1$ after 500 cycles at $1.0 \mathrm{Ag}-1$ with a capacity fading of $0.06 \%$ per cycle. The \\ cycling stability as well as rate capability of N/S-rGO@ZnSnS3 are superior to those of the pristine hollow \\ $\mathrm{ZnSnS3}$ cubes/un-doped rGO composite. It is convinced that the electrode performance is strongly rooted \\ in its structural conformation. Furthermore, the structural evolutions of $\mathrm{ZnSnS3}$ reactions with sodium are \\ revealed by in situ X-ray diffraction combined with ex situ X-ray photoelectron spectroscopy, which \\ provides a valuable revelation for the understanding of reaction mechanism toward bimetallic sulfides \\ and beyond. \\ Disciplines \\ Engineering | Physical Sciences and Mathematics

\section{Publication Details} \\ Liu, X., Hao, Y., Shu, J., Sari, H., Lin, L., Kou, H., Li, J., Liu, W., Yan, B., Li, D., Zhang, J. \& Li, X. (2019). \\ Nitrogen/sulfur dual-doping of reduced graphene oxide harvesting hollow ZnSnS3 nano-microcubes with \\ superior sodium storage. Nano Energy, 57 414-423.

\section{Authors} \\ Xiaojing Liu, Youchen Hao, Jie Shu, Hirbod Maleki Kheimeh Sari, Liangxu Lin, Huari Kou, Jianwei Li, Wen \\ Liu, Bo Yan, Dejun Li, Jiujun Zhang, and Xifei Li
}




\section{Author's Accepted Manuscript}

Nitrogen/Sulfur Dual-Doping of Reduced Graphene Oxide Harvesting Hollow $\mathrm{ZnSnS}_{3}$ NanoMicrocubes with Superior Sodium Storage

Xiaojing Liu, Youchen Hao, Jie Shu, Hirbod Maleki Kheimeh Sari, Liangxu Lin, Huari Kou, Jianwei Li, Wen Liu, Bo Yan, Dejun Li, Jiujun Zhang, Xifei Li

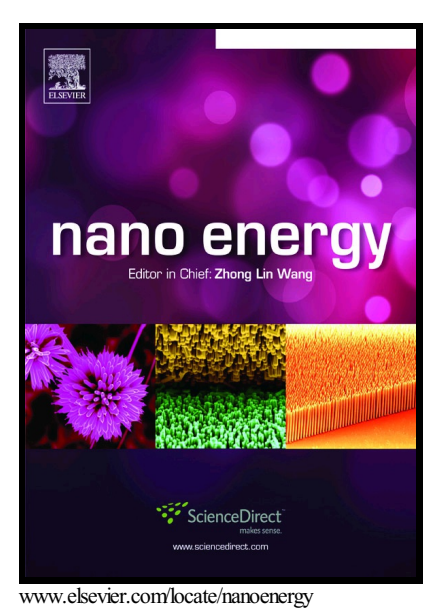

PII: $\quad$ S2211-2855(18)30929-7

DOI: $\quad$ https://doi.org/10.1016/j.nanoen.2018.12.024

Reference: NANOEN3272

To appear in: Nano Energy

Received date: 4 November 2018

Revised date: 8 December 2018

Accepted date: 9 December 2018

Cite this article as: Xiaojing Liu, Youchen Hao, Jie Shu, Hirbod Maleki Kheimeh Sari, Liangxu Lin, Huari Kou, Jianwei Li, Wen Liu, Bo Yan, Dejun Li, Jiujun Zhang and Xifei Li, Nitrogen/Sulfur Dual-Doping of Reduced Graphene Oxide Harvesting Hollow $\mathrm{ZnSnS}_{3}$ Nano-Microcubes with Superior Sodium Storage, Nano Energy, https://doi.org/10.1016/j.nanoen.2018.12.024

This is a PDF file of an unedited manuscript that has been accepted for publication. As a service to our customers we are providing this early version of the manuscript. The manuscript will undergo copyediting, typesetting, and review of the resulting galley proof before it is published in its final citable form. Please note that during the production process errors may be discovered which could affect the content, and all legal disclaimers that apply to the journal pertain. 


\section{Nitrogen/Sulfur Dual-Doping of Reduced Graphene Oxide Harvesting Hollow $\mathrm{ZnSnS}_{3}$ Nano-Microcubes with Superior Sodium Storage}

Xiaojing Liu ${ }^{\mathrm{a}}$, Youchen $\mathrm{Hao}^{\mathrm{b}}$, Jie Shu ${ }^{\mathrm{c}}$, Hirbod Maleki Kheimeh Sari ${ }^{\mathrm{b}}$, Liangxu Lin ${ }^{\mathrm{d}}$, Huari Kou ${ }^{\mathrm{b}}$, Jianwei Li ${ }^{\mathrm{b}}$, Wen Liu ${ }^{\mathrm{b}}$, Bo Yan ${ }^{\mathrm{b}}$, Dejun $\mathrm{Li}^{\mathrm{a}}$, Jiujun Zhang ${ }^{\mathrm{b}, \mathrm{e}}, \mathrm{Xifei} \mathrm{Li}^{\mathrm{a}}$,b,1

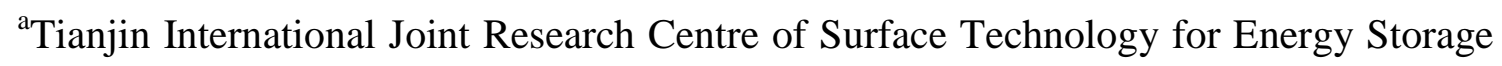
Materials, College of Physics and Materials Science, Tianjin Normal University, Tianjin 300387, China.

${ }^{\mathrm{b}}$ Institute of Advanced Electrochemical Energy \& School of Materials Science and Engineering, Xi'an University of Technology, Xi'an 710048, China

${ }^{c}$ Faculty of Materials Science and Chemical Engineering, Ningbo University, Ningbo 315211, China

${ }^{\mathrm{d}}$ Australia Institute of Innovative Materials, University of Wollongong, Wollongong 2500, Australia

${ }^{\mathrm{e}}$ Department of Chemistry, College of Sciences/Institute for Sustainable Energy, Shangh ai University, Shanghai, China, 200444

xfli2011@hotmail.com

\section{Abstract}

Bimetallic sulfides have exhibited promising applications in advanced sodium-ion batteries (SIBs) due to their relatively high electronic conductivity and electrochemical

${ }^{1}$ Tel: +86-22-23766526; fax: +86-22-23766503 
activity. In this study, for the first time, the N/S dual-doped reduced graphene oxide (rGO) encapsulating hollow $\mathrm{ZnSnS}_{3}$ nano-microcubes (N/S-rGO@ $\mathrm{ZnSnS}_{3}$ ) is designed to improve the sluggish reaction kinetics, poor cycling stability and unsatisfactory rate capability of metal sulfides. To examine this design, the cycling stability and rate capability of the desired anode material is studied in detail. It is found that N/S-rGO@ $\mathrm{ZnSnS}_{3}$ hybrid delivers a high discharge capacity of $501.7 \mathrm{mAh} \mathrm{g}^{-1}$ after 100 cycles at $0.1 \mathrm{~A} \mathrm{~g}^{-1}$, and a reversible capacity of $290.7 \mathrm{mAh} \mathrm{g}^{-1}$ after 500 cycles at $1.0 \mathrm{~A}$ $\mathrm{g}^{-1}$ with a capacity fading of $0.06 \%$ per cycle. The cycling stability as well as rate capability of N/S-rGO@ $\mathrm{ZnSnS}_{3}$ are superior to those of the pristine hollow $\mathrm{ZnSnS}_{3}$ cubes/un-doped rGO composite. It is convinced that the electrode performance is strongly rooted in its structural conformation. Furthermore, the structural evolutions of $\mathrm{ZnSnS}_{3}$ reactions with sodium are revealed by in situ X-ray diffraction combined with ex situ X-ray photoelectron spectroscopy, which provides a valuable revelation for the understanding of reaction mechanism toward bimetallic sulfides and beyond. 


\section{ACCEPTED MANUSCRIPT}

\section{Graphical Abstract}

Hollow $\mathrm{ZnSnS}_{3}$ nano-microcubes encapsulated into N/S dual-doped $\mathrm{rGO}$ presents superior cycling stability and rate capability for $\mathrm{Na}$ storage due to the simultaneous improvements in structural stability, electronic conductivity, electrochemical activity, and reaction kinetics.

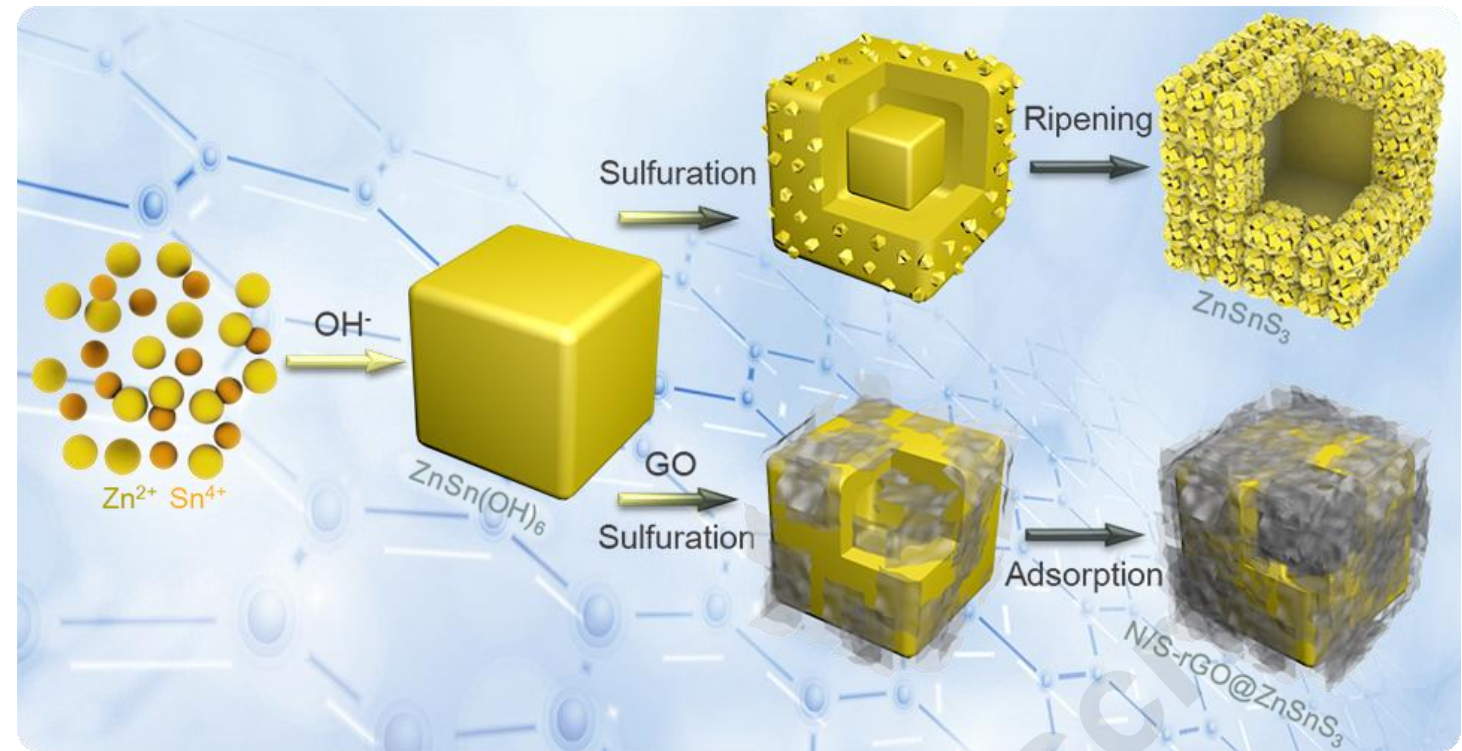

Keywords: bimetallic sulfides; dual-doped graphene; sodium-ion batteries; reaction kinetics; sodiation mechanism

\section{Introduction}

To date, various cathode materials of sodium ion batteries (SIBs) have been reported, such as layered transition metal oxides, sulfides, phosphates, Prussian blue analogues, etc ${ }^{[1-4]}$. And stagnant development has been required to focus on anode materials in SIBs. Unfortunately, the commercialized graphite anode of lithium ion batteries (LIBs) suffers from a low capacity of less than $35 \mathrm{mAh} \mathrm{g}^{-1}$ for $\mathrm{SIBs}^{[5-7]}$. Furthermore, most anode materials of LIBs lose their superior electrochemical properties when functioning as SIB electrodes due to the bigger radius of sodium ions 


\section{ACCEPTED MANUSCRIPT}

$\left(\mathrm{Li}^{+}: 0.76 \AA \mathrm{Na}^{+}: 1.02 \AA\right)$, which results in a sluggish electrochemical reaction kinetics.

Consequently, it is of high necessity to explore appropriate anode candidates with excellent rate capability and prominent capacity retention for $\mathrm{SIBs}^{[8,9]}$.

Currently, monometal sulfides (such as $\mathrm{TiS}_{2}{ }^{[10]}, \mathrm{SnS}_{2}{ }^{[11]}, \mathrm{MoS}_{2}{ }^{[12]}, \mathrm{CoS}_{2}{ }^{[13]}$, $\mathrm{Sb}_{2} \mathrm{~S}_{3}{ }^{[14]}$, etc.) have been well documented as anode materials for SIBs. Compared with monometal sulfides, bimetallic sulfides show obvious advantages deriving from their relatively high electronic conductivity and electrochemical activity. In particular, two metal elements react with sodium on the basis of alloying/dealloying processes with significant effect of self-matrix and self-conductivity. In fact, the non-reacted component can act as a temporary buffer/conductor for the reacted one due to the difference in redox potential ${ }^{[15,16]}$, as we previously reported so-called "synergistic effect" $^{\text {"[17] }}$. Despite these advantages, the challenges still remain in bimetallic sulfides in terms of sluggish reaction kinetics, poor cycling stability and unsatisfactory rate performance, originating from the big radius of $\mathrm{Na}^{+}$and large volume fluctuation during sodiation/desodiation processes ${ }^{[18-20]}$.

Many studies have focused on the mitigation of the intrinsic issues of bimetallic sulfides ${ }^{[15,21-24]}$. One prevailing way is to build a unique nanostructure which could significantly shorter the transport paths of ions and electrons, and consequently improve electrochemical reaction kinetics ${ }^{[25,26]}$. Among numerous nanostructures, hollow nanostructured materials have been proved to possess prominent virtues including: (i) increasing electrode/electrolytes contact area and improving electrode wettability; (ii) easily accommodating the volume fluctuation and maintaining the cycling stability ${ }^{[16,26]}$. 


\section{ACCEPTED MANUSCRIPT}

Using Prussian blue precursors, for example, Chen et al. demonstrated the advantages of hollow $\mathrm{Co}_{8} \mathrm{FeS}_{8}$ nanocubes with superior rate capacities and cycle stabilities, stemming from high surface area, small charge transfer resistance, and lasting tolerability for volume change ${ }^{[15]}$. Another effective approach is to introduce highly conductive substrates into bimetallic sulfides to construct a fast electron conduction path and suppress agglomeration of the active material upon cycling, such as porous carbon deriving from the pyrolysis of polymer or metal organic frameworks ${ }^{[21-24]}$. As an example, Dong et al. reported the formation of $\mathrm{ZnS}_{-} \mathrm{Sb}_{2} \mathrm{~S}_{3} @ \mathrm{C}$ polyhedron consisting of $\mathrm{ZnS}$ inner-core and $\mathrm{Sb}_{2} \mathrm{~S}_{3} @ \mathrm{C}$ double-shell using polymeric resorcinol-formaldehyde as carbon source, which shows the good sodium storage with a high specific capacity of $630 \mathrm{mAh} \mathrm{g}^{-1}$ at a current density of $0.1 \mathrm{~A} \mathrm{~g}^{-1}$ after 120 cycles $^{[21]}$. To the best of our knowledge, in comparison to pyrolytic porous carbon, carbon nanotubes, and carbon nanosheets, reduced graphene oxide (rGO) may be a more desirable conductive matrix to boost the anode performance owing to its large surface area, high electrical conductivity and outstanding flexibility to relax the induced pulvarization ${ }^{[27,28]}$. Interestingly, the high mouldability often exists in the preparation process of $\mathrm{rGO}$, including handily building unique textures (anchored, layered, or wrapped style) and lightly designing doped ones (single or multi-element doping) ${ }^{[29-33]}$. Note that the non-metallic heteroatom $(\mathrm{N}, \mathrm{P}, \mathrm{S}$, or $\mathrm{B})$ doping into $\mathrm{rGO}$ is generally effective in tuning its electrical properties and chemical activity for $\mathrm{Li}^{+} / \mathrm{Na}^{+}$storage ${ }^{[34-36]}$, as $\mathrm{N}$-doped pyrolytic carbon decorating the bi-metal sulfides anode materials presented impelling performance in $\mathrm{SIBs}^{[23,24]}$. To break the limit of the doping level introduced by a single 
heteroatom, however, it is highly desire to dual-dope rGO with two different heteroatoms. Our previous results demonstrate that N/S dual-doping into rGO provides a series of collaborative advantages for energy storage over the single one: (i) suppressing the aggregation of the prepared rGO owing to the strong polarity of the doping area; (ii) increasing the electric conductivity by lowering the semiconducting gap; (iii) enhancing the diffusion and storage of alkali mental ions due to the more high-electronegativity of deficiencies easily attracting the positive ions; (iv) reinforcing the structural stability because of the physical/chemical adsorption between active material and dual-doped $\mathrm{rGO}^{[37,38]}$. Unfortunately, the ingenious incorporation of hollow nanostructured bimetallic sulfides with the dual-doped doped rGO to generate a more desirable composite has been scarcely reported so far. Therefore, it has been challenging to build such an advanced composite for SIBs.

In this work, a facile two-step strategy is utilized to design N/S dual-doped rGO encapsulating hollow $\mathrm{ZnSnS}_{3}$ nano-microcubes (N/S-rGO@ $\mathrm{ZnSnS}_{3}$ ) for the first time, considering the high capacity of $\mathrm{Zn} / \mathrm{Sn}$ and the so-called "synergistic effect" during alloying/dealloying processes. The resultant N/S-rGO@ $\mathrm{ZnSnS}_{3}$ anode exhibits superior sodium storage performance and improved reaction kinetics compared with the pristine hollow $\mathrm{ZnSnS}_{3}$ nano-microcubes and un-doped rGO composite.

\section{Experimental section}

2.1 Materials preparation

2.1.1 Synthesis of $\mathrm{ZnSn}(\mathrm{OH})_{6}$ cubes 
$\mathrm{ZnSn}(\mathrm{OH})_{6}$ cubes were prepared via a facile co-precipitation method. In a typical synthesis, $50 \mathrm{~mL}$ of ethanol solution of $\mathrm{SnCl}_{4} \cdot 5 \mathrm{H}_{2} \mathrm{O}(0.01 \mathrm{~mol})$ was added into $100 \mathrm{~mL}$ of a mixture aqueous solution containing $0.01 \mathrm{~mol} \mathrm{ZnCl}_{2}$ and 0.01 mol sodium citrate under stirring, followed by dropwise addition of $50 \mathrm{~mL}$ of $2 \mathrm{M} \mathrm{NaOH}$ solution at room temperature. After $1 \mathrm{~h}$, the white precipitates were separated by centrifugation and washed with deionized water and ethanol. Finally, the precursor $\mathrm{ZnSn}(\mathrm{OH})_{6}$ cubes were obtained after drying in a vacuum at $60{ }^{\circ} \mathrm{C}$ overnight.

\subsubsection{Synthesis of the N/S-rGO@ $\mathrm{ZnSnS}_{3}$ composite}

Graphite oxide (GO) was fabricated using a modified Hummers method, as previously reported by our group ${ }^{[39]}$. Firstly, the obtained GO was dispersed in deionized water by ultrasonic cell disruption for $0.5 \mathrm{~h}$ to form a black solution with 2.0 $\mathrm{mg} \mathrm{mL} \mathrm{m}^{-1}$. Afterwards, $60 \mathrm{mg} \mathrm{ZnSn}(\mathrm{OH})_{6}$ powder and $0.49 \mathrm{~g} \mathrm{Na}_{2} \mathrm{~S}$ were dispersed in 30 $\mathrm{mL}$ deionized water under stirring, followed by addition of thiourea and as-prepared GO dispersion (the GO and thiourea in a mass ratio of 1:30). Subsequently, the reaction mixture was transferred into a $50 \mathrm{~mL}$ Teflon-lined sealed autoclave and treated at $180{ }^{\circ} \mathrm{C}$ for $18 \mathrm{~h}$. After cooled to room temperature, the desired products were collected by centrifugation, washed with deionized water and ethanol, and dried in a vacuum oven at $60{ }^{\circ} \mathrm{C}$ for $12 \mathrm{~h}$. As a comparison, a series of control samples were prepared via similar procedures respectively without adding thiourea and GO dispersion (for $\mathrm{ZnSnS}_{3}$ ), $\mathrm{ZnSn}(\mathrm{OH})_{6}$ and $\mathrm{Na}_{2} \mathrm{~S}$ (for $\mathrm{N} / \mathrm{S}$ codoped $\mathrm{rGO}$ ), and thiourea (for rGO@ $\left.\mathrm{ZnSnS}_{3}\right)$. 
2.2 Materials characterization

Field-emission scanning electron microscopy (FESEM) coupled with energy dispersive spectroscopy (EDS) mapping images were taken using a Hitachi SU8010 field-emission scanning electron microscope. The microstructure of the samples was verified using a transmission electron microscopy (TEM, JEOL JEM-3000F) with an accelerating voltage of $200 \mathrm{kV}$. The X-ray diffraction (XRD) and in situ XRD measurements were performed on the Bruker AXS D8 advance X-ray diffractometer at the $2 \theta$ range of $10-70^{\circ}$ with $\mathrm{Cu} \mathrm{K}$ radiation $(\lambda=1.5405 \AA)$. The content of $\mathrm{rGO}$ in the target products was estimated using a thermogravimetric analysis (TGA, TA SDT-Q600) from $25-1000{ }^{\circ} \mathrm{C}$ at $10{ }^{\circ} \mathrm{C} \mathrm{min}{ }^{-1}$ under air atmosphere. Raman analysis was conducted on a confocal micro Raman spectrometer with Lab RAM HR800 system (HORIBA) in the range of $300-2000 \mathrm{~cm}^{-1}$. X-ray photoelectron spectroscopy (XPS, PHI5000VersaProbe) with $\mathrm{Al} \mathrm{K}_{\alpha}$ radiation as the $\mathrm{X}$-ray source for excitation was obtained to characterize the elemental information of the final materials.

\subsection{Electrochemical measurements}

For the working electrode, $70 \mathrm{wt} \%$ active materials, $20 \mathrm{wt} \%$ acetylene black, and 10 wt $\%$ polyvinylidene fluoride binder dispersed in N-methyl pyrrolidinone solvent. Then, the resultant well-proportioned slurry was spread on $\mathrm{Cu}$ foil and dried at $80{ }^{\circ} \mathrm{C}$ in a vacuum oven overnight. The 2032 typed coin cells were assembled in an Ar-filled dry glovebox using $\mathrm{Na}$ foil as the negative electrode, glass fiber as the separator, and $1 \mathrm{M}$ of $\mathrm{NaClO}_{4}$ in ethylene carbonate (EC) and propylene carbonate (PC) $(1: 1, \mathrm{vol} \%)$ with $5 \mathrm{wt} \%$ 


\section{ACCEPTED MANUSCRIPT}

of FEC as the electrolyte. The galvano-static charge/discharge tests at various current densities were recorded using a Land battery testing system (LANHECT2001A) in the voltage range of $0.01-3.0 \mathrm{~V}$ (vs. $\mathrm{Na} / \mathrm{Na}^{+}$). Cyclic voltammograms $(\mathrm{CV})$ was collected using a VersaSTAT 4 electrochemical work station at the scan rate of $0.1 \mathrm{mV} \mathrm{s}^{-1}$. An AC amplitude of $5 \mathrm{mV}$ was employed to measure electrochemical impedance spectroscopy (EIS) with the frequency range from $0.01 \mathrm{~Hz}$ to100 kHz.

\section{Results and Discussion}

\subsection{Morphology and structure characterization}

The formation processes of $\mathrm{ZnSnS}_{3}$ and N/S-rGO@ $\mathrm{ZnSnS}_{3}$ are depicted in Scheme 1. In the first step, the precursor $\mathrm{ZnSn}(\mathrm{OH})_{6}$ is generated from a mixed solution of $\mathrm{Zn}^{2+}$ and $\mathrm{Sn}^{4+}$ via a co-precipitation mothed with a strong alkaline solution as precipitator. The obtained precursor entirely consists of uniform cubes with relatively smooth surface and an average width of $\sim 2 \mu \mathrm{m}$ (Fig. S1a and b). As shown in Fig. S1c and d, these microcubes are the solid corporeity with high crystallinity. In the following hydrothermal sulfuration with $\mathrm{Na}_{2} \mathrm{~S}$, the solid precursor of $\mathrm{ZnSn}(\mathrm{OH})_{6}$ can be chemically turned into hollow $\mathrm{ZnSnS}_{3}$ nano-microcubes. The evolution of this hollow structure can be attributed to the diffusion-controlled effect, which has been extensively employed in the creation of interior voids for metal sulfides ${ }^{[40,41]}$. With the participation of GO dispersion, not only is the GO effectively reduced and doped with the assistance of the doping agent thiourea ${ }^{[37,38]}$, but also uniformly absorbed onto the surface of cubes 


\section{ACCEPTED MANUSCRIPT}

due to the electrostatic attraction and the effect of total surface energies ${ }^{[30]}$. Commendably, the implementation of rGO doping and $\mathrm{ZnSn}(\mathrm{OH})_{6}$ sulfuration occurs via a facile one-step hydrothermal treatment.

The morphologies of $\mathrm{ZnSnS}_{3}$ and N/S-rGO@ $\mathrm{ZnSnS}_{3}$ were initially determined via FE-SEM. Fig. 1a shows $\mathrm{ZnSnS}_{3}$ cubes prepared by the hydrothermal sulfidation of $\mathrm{ZnSn}(\mathrm{OH})_{6}$ for $9 \mathrm{~h}$. Compared with the precursor, the relatively coarse surface of $\mathrm{ZnSnS}_{3}$ cubes is observed (Fig. S2a). While, with the reaction time prolonging to $18 \mathrm{~h}$, this intermediate state suffers from the overgrowth and becomes more rough induced by the fast anion exchange (Fig. S2b). Close observation of Fig. 1b indicates that the final $\mathrm{ZnSnS}_{3}$ cube with obvious porosity is composed of interconnected nanocube clusters. The energy dispersive spectroscopy (EDS) mappings of final $\mathrm{ZnSnS}_{3}$ in Fig. 1c confirm that the element mappings of $\mathrm{Zn}, \mathrm{Sn}$ and $\mathrm{S}$ display the almost identical morphology with that of the parent material, implying the adequately sulfuration of $\mathrm{ZnSn}(\mathrm{OH})_{6}$. Along with the GO dispersion participating in hydrothermal reaction, the resulting $\mathrm{ZnSnS}_{3}$ nano-microcubes are uniformly embedded in three-dimensional interlaced rGO (Fig. 1d), achieving the construction of conductive network. Noticeably, the obtained $\mathrm{ZnSnS}_{3}$ nano-microcubes maintain the monodispersed texture and are wrapped by transparent voile-like rGO evenly (Fig. 1e). The close observation in Fig. If confirms that the surface of $\mathrm{ZnSnS}_{3}$ seems visibly smooth, indicating that the rGO serving as a diffusion barrier for growth substance can visibly suppress the surface coarsing of $\mathrm{ZnSnS}_{3}$ nano-microcubes ${ }^{[30]}$. Additionally, the EDS mappings of N/S-rGO@ $\mathrm{ZnSnS}_{3}$ reveal the high elemental purity of $\mathrm{Zn}, \mathrm{Sn}$, and $\mathrm{S}$ (Fig. 1g). Notably, the $\mathrm{N}$ and $\mathrm{C}$ signals can be 
easily detected (Fig. 1g), suggesting the effective doping of rGO and its sophisticated combination with $\mathrm{ZnSnS}_{3}$. The TEM image of $\mathrm{ZnSnS}_{3}$ shown in Fig. 1h exhibits a rough appearance with legible edge width of nearly $400 \mathrm{~nm}$, in which the inner cavity is evidently exposed, suggesting the exhausted precursor kernel by the anion exchange. From Fig. $1 \mathrm{j}$ and $\mathrm{S} 1 \mathrm{e}$, conversely, the $\mathrm{ZnSnS}_{3}$ cubes with the smooth surface wrapped by rGO can be clearly observed. Meanwhile, the hollow texture of $\mathrm{ZnSnS}_{3}$ is further confirmed by Fig. S1f, matching well with the SEM result (Fig. 1f). The HRTEM image captured from the wall edge of nano-microcubes reveals that the obtained $\mathrm{ZnSnS}_{3}$ possesses high crystallinity (Fig. 1i), and the crystallinity is not significantly affected by the presence of rGO (Fig. 1k).

The X-ray powder diffraction (XRD) is conducted to further reveal the phase purity and structure of the tested materials. In the XRD pattern of the solid precursor, the characteristic peaks are in a good agreement with the standard $\mathrm{ZnSn}(\mathrm{OH})_{6}$ (JCPDS Card no. 33-1376) (Fig. S3a). Fig. 2a shows that the diffraction peaks of precursor completely disappear after sulfuration, and all of the diffraction peaks correspond to the standard data (JCPDS Card no. 28-1486), further confirming the desired $\mathrm{ZnSnS}_{3}$ with high purity and the complete conversion of $\mathrm{ZnSn}(\mathrm{OH})_{6}$. For N/S-rGO@ZnSnS 3 (Fig. 2a), no significant observable peaks can be detected by comparison with $\mathrm{ZnSnS}_{3}$ diffraction peaks because $\mathrm{rGO}$ reveals negligible effect on the phase purity and crystallinity of $\mathrm{ZnSnS}_{3}$. The carbon content in N/S-rGO@ $\mathrm{ZnSnS}_{3}$ hybrid is evaluated to be approximately $7.8 \mathrm{wt} \%$ based on the thermogravimetric analysis (TGA) (Fig. S3b). Specifically, the initial weight loss from 25 to $200{ }^{\circ} \mathrm{C}$ 


\section{ACCEPTED MANUSCRIPT}

indicates the loss of adsorbed water molecules. The weight loss of about 7.8 wt $\%$ from 200 to $400{ }^{\circ} \mathrm{C}$ can be mainly ascribed to oxidization of rGO. And with heating up to $600{ }^{\circ} \mathrm{C}$, the further weight loss of the composite is due to the oxidization of $\mathrm{ZnSnS}_{3}$. As expected, the response signals of rGO are observed in the Raman spectra (Fig. 2b). The obvious peaks located at $472.34,1455.71$ and $1514.94 \mathrm{~cm}^{-1}$ are attributed to $\mathrm{ZnSnS}_{3}$. The two characteristic bands at 1357.6 and $1591.3 \mathrm{~cm}^{-1}$ consist with the defective and disordered carbon form of the graphitic layer ( $D$ band) and the vibration of the $\mathrm{sp}^{2}$-bonded ordered graphitic carbon ( $\mathrm{G}$ band), respectively ${ }^{[19,31,38]}$. Notably, the intensity ratios of $\mathrm{I}_{\mathrm{D}} / \mathrm{I}_{\mathrm{G}}$ for $\mathrm{N} / \mathrm{S}$ codoped $\mathrm{rGO}$ and $\mathrm{rGO}$ are calculated to be 1.38 and 1.27, respectively, suggesting the formation of N/S codoped $\mathrm{rGO}$ with more defects and edge plane exposure ${ }^{[19,37,38]}$. Moreover, the Brunauer-Emmett-Teller (BET) specific surface areas of $\mathrm{ZnSnS}_{3}$, N/S-rGO@ $\mathrm{ZnSnS}$, and N/S-rGO are measured to be 36.31, 70.51 , and $180.48 \mathrm{~m}^{2} \mathrm{~g}^{-1}$, respectively (Fig. 2c). It is due to the fact that the introduction of N/S-rGO can moderately increase the specific surface area of N/S-rGO@ $\mathrm{ZnSnS}_{3}$, and thus regulate the electrode/electrolytes contact area ${ }^{[30,37,38]}$. X-ray photoelectron spectroscopy (XPS) is carried out to characterize the elemental composition and chemical bonding state of the N/S-rGO@ $\mathrm{ZnSnS}_{3}$. Primarily, the high-resolution N 1s spectrum (Fig. 2d) contains three types of N, namely, Graphite N (401.2 eV), Pyrrolic N $(400.2 \mathrm{eV})$, and Pyridinic N $(398.5 \mathrm{eV})^{[37,38]}$. Meanwhile, in the S 2p region (Fig. 2e), the peaks centered at 161.7 and $162.5 \mathrm{eV}$ are attributable to $\mathrm{S} 2 \mathrm{p} 3 / 2$ and $2 \mathrm{p} 1 / 2$ of $\mathrm{Sn}-\mathrm{S}$, and the peaks with binding energies of 161.7 and $162.9 \mathrm{eV}$ are assigned to $\mathrm{S} 2 \mathrm{p} 3 / 2$ and $2 \mathrm{p} 1 / 2$ of $\mathrm{Zn}-\mathrm{S}$, and the peak centered at $163.8 \mathrm{eV}$ belongs to $\mathrm{C}-\mathrm{S}-\mathrm{C}$ as well. Additionally, 


\section{ACCEPTED MANUSCRIPT}

Fig. $2 \mathrm{f}$ presents the de-convoluted C 1 s spectrum. The peaks centered at $284.6 \mathrm{eV}$ and $288.1 \mathrm{eV}$ belonged to $(\mathrm{C}=\mathrm{C}, \mathrm{C}-\mathrm{C})$ and $\mathrm{O}-\mathrm{C}=\mathrm{O}$. Also the $\mathrm{C}-\mathrm{N}$ and $\mathrm{C}-\mathrm{S}$ bonds which reveal the potential reactions between functional groups in $\mathrm{GO}$ and sulfourea can be detected by the peaks at $285.7 \mathrm{eV}$ and $285.1 \mathrm{eV}$, respectively ${ }^{[31,38]}$. All the observations unambiguously demonstrate the effective co-doping of $\mathrm{S}$ and $\mathrm{N}$ into rGO. In addition, the high-resolution spectra of $\mathrm{Zn} 2 \mathrm{p}$ and $\mathrm{Sn} 3 \mathrm{~d}$ for $\mathrm{ZnSnS}_{3}$ (Fig. S3c) are highly consistent with those of N/S-rGO@ $\mathrm{ZnSnS}_{3}$ (not shown), but the $\mathrm{S} 2 \mathrm{p}$ spectrum of $\mathrm{ZnSnS}_{3}$ shown in Fig. S3d visibly differs from that of $\mathrm{N} / \mathrm{S}-\mathrm{rGO} @ \mathrm{ZnSnS}_{3}$ (Fig. 2e), which further verifies the doping effectiveness.

3.2 Sodium storage of the as-prepared electrodes

Fig. 3a presents the initial four cyclic voltammogram (CV) curves of $\mathrm{N} / \mathrm{S}-\mathrm{rGO} @ \mathrm{ZnSnS}_{3}$ anode at $0.1 \mathrm{mV} \mathrm{s}^{-1}$ over the voltage range of $0.01-3.0 \mathrm{~V}$. In the $1^{\text {st }}$ cycle, the cathodic peak at $1.16 \mathrm{~V}$ is ascribed to sodium intercalation into $\mathrm{ZnSnS}_{3}$ and its subsequent conversion ${ }^{[9,22,24,42]}$, while the peak at $0.27 \mathrm{~V}$ may mainly result from the alloying process ${ }^{[21,31,42]}$. Note that this alloying reduction peak is split into two small peaks centered at 0.67 and $0.25 \mathrm{~V}$ in succedent scans, suggesting the step-by-step reaction processes. In the first anodic sweep, the oxidation peaks at 0.73 and $1.05 \mathrm{~V}$ are in response to the desodiation reactions of $\mathrm{Na}-\mathrm{Zn}$ and $\mathrm{Na}-\mathrm{Sn}^{[8,21,22]}$. Meanwhile, the anodic peaks at higher voltage of 1.58 and $2.15 \mathrm{~V}$ are attributed to the further oxidation of $\mathrm{Zn}$ and $\mathrm{Sn}^{[7,8,21,42]}$. Another distinct feature observed in Fig. 3a is the existence of a large irreversible capacity upon the first reduction process, which is related to the 


\section{ACCEPTED MANUSCRIPT}

generation of solid electrolyte interphase (SEI) film as well as the irreversible decomposition of $\mathrm{ZnSnS}_{3}$. As shown in Fig. S4a, the pristine $\mathrm{ZnSnS}_{3}$ anode shows the similar electrochemical behaviors with that of N/S-rGO@ $\mathrm{ZnSnS}_{3}$, but the relatively large polarization can be evidently observed, implying poor electrochemical properties. On the other hand, the redox peak currents of N/S-rGO@ $\mathrm{ZnSnS}_{3}$ are higher than those of $\mathrm{ZnSnS}_{3}$ (Fig. S4a), revealing the high electrochemical activity of the composite over the pristine one. The follow-up overlapped feature of the $\mathrm{CV}$ profiles for N/S-rGO@ZnSnS 3 indicates the excellent reversibility and stability for sodium storage.

Fig. 3b shows the charge/discharge behaviors of N/S-rGO@ $\mathrm{ZnSnS}_{3}$ at the current density of $0.1 \mathrm{~A} \mathrm{~g} \mathrm{~g}^{-1}$. In the first cycle, two flat discharge plateaus at voltage range of 1.25-1.10 $\mathrm{V}$ and 0.32-0.21 $\mathrm{V}$ are observed, matching well with the CV data. The initial discharge/charge processes record high specific capacities of 1230.7 and $655.7 \mathrm{mAh} \mathrm{g}^{-1}$, respectively, and the second discharge specific capacity drops to $696.3 \mathrm{mAh} \mathrm{g}^{-1}$. Such big capacity decay is mainly attributed to the formation of SEI film as well as the irreversible decomposition of $\mathrm{ZnSnS}_{3}$. Following that, a relatively stable reversible specific capacity of $501.7 \mathrm{mAh} \mathrm{g}^{-1}$ can be delivered after 100 cycles with high Coulombic efficiency close to $100 \%$. In contrast, the $\mathrm{ZnSnS}_{3}$ anode shows a sharp capacity loss and only maintains the discharge specific capacity of $17.1 \mathrm{mAh} \mathrm{g}^{-1}$ after 100 cycles (Fig. S4b). By increasing the current densities, when cycled stepwise at 0.2 , 0.4, 1.0 and $2.0 \mathrm{~A} \mathrm{~g}^{-1}$, the composite anode can also deliver the reversible capacities of 498.5, 415.0, 351.4 and $256.6 \mathrm{mAh} \mathrm{g}^{-1}$, respectively, indicting the remarkable rate capability and speedy reaction kinetics (Fig. 3c). This conclusion can be further 


\section{ACCEPTED MANUSCRIPT}

confirmed in Fig. 3d. It is obvious that N/S-rGO@ $\mathrm{ZnSnS}_{3}$ anode displays impressive rate capacities. Particularly, the reversible capacity in N/S-rGO@ $\mathrm{ZnSnS}_{3}$ is almost fully recovered (531.4 $\mathrm{mAh} \mathrm{g}^{-1}$ ) when the current density decreases back to $0.1 \mathrm{~A} \mathrm{~g}^{-1}$ after 80 cycles. Conversely, both $\mathrm{N} / \mathrm{S}-\mathrm{rGO}$ and $\mathrm{ZnSnS}_{3}$ electrodes manifest relatively weak rate capability. In particular, the pure $\mathrm{ZnSnS}_{3}$ anode suffers from an extremely sharp capacity decay at the same stepwise rates, presenting low discharge specific capacities of 190.3 and $88.2 \mathrm{mAh} \mathrm{g}^{-1}$ at 0.2 and $0.4 \mathrm{~A} \mathrm{~g}^{-1}$, respectively. Even worse, the negligible capacities at 1.0 and $2.0 \mathrm{~A} \mathrm{~g}^{-1}$ are obtained with an unsatisfactory recovering, following the regression of current densities (Fig. 3d). These observations demonstrate that the presence of N/S-rGO conspicuously improves the electrochemical performance of $\mathrm{ZnSnS}_{3}$ anode. To further reveal the effect of N/S-rGO on $\mathrm{ZnSnS}_{3}$, Fig. 3e shows the relative capacity retentions of $\mathrm{ZnSnS}_{3}, \mathrm{~N} / \mathrm{S}-\mathrm{rGO}$, and N/S-rGO@ $\mathrm{ZnSnS}_{3}$. Manifestly, the capacity retention of N/S-rGO is close to $25 \%$, which is much better than that of pure $\mathrm{ZnSnS}_{3}$ (3.6\%). More strikingly, these values are far below that one achieved by N/S-rGO@ZnSnS 3 . To be specific, the N/S-rGO@ $\mathrm{ZnSnS}_{3}$ anode displays dramatically improved electrochemical performance with $40.3 \%$ relative capacity retention at $2.0 \mathrm{~A}$ $\mathrm{g}^{-1}$ due to the efficacy of N/S-rGO. Inspired by superior rate capability, the long-term cycling performance of the obtained anodes at $1.0 \mathrm{~A} \mathrm{~g}^{-1}$ is performed in Fig. 3f. After 500 cycles, the N/S-rGO@ $\mathrm{ZnSnS}_{3}$ anode still retains a high discharge specific capacity of $290.7 \mathrm{mAh} \mathrm{g}^{-1}$ with the Coulombic efficiency close to $100 \%$ and a capacity retention of $68.2 \%$ in comparison with the value in the $2^{\text {nd }}$ cycle. In contrast, the N/S-rGO electrode delivers a reversible capacity of $107.4 \mathrm{mAh} \mathrm{g}^{-1}$ after 500 cycles with a 


\section{ACCEPTED MANUSCRIPT}

capacity retention of $41.0 \%$, and the worst result belongs to $\mathrm{ZnSnS}_{3}$ with almost zero capacity in its 90th cycle. Therefore, it can be concluded that the encapsulation of hollow $\mathrm{ZnSnS}_{3}$ nano-microcubes with $\mathrm{N} / \mathrm{S}$ dual doped $\mathrm{rGO}$ engenders a tremendous influence on the rate capacity and cycling performance of $\mathrm{Na}^{+}$storage. Moreover, to further demonstrate the doping function in N/S-rGO@ $\mathrm{ZnSnS}_{3}$ composite, the electrochemical performance of $\mathrm{rGO} @ \mathrm{ZnSnS}_{3}$ is correspondingly evaluated. As shown in Fig. S4c and d, the N/S-rGO@ $\mathrm{ZnSnS}_{3}$ composite exhibits a higher rate capacity and more excellent cycling stability than $\mathrm{rGO} @ \mathrm{ZnSnS}_{3}$, which can be mainly attributed to the increased electric conductivity and electroactive sites created by nitrogen and sulfur doping. ${ }^{[31,37,38]}$ Regarding the stability of N/S-rGO@ $\mathrm{ZnSnS}_{3}$, Fig. S5 displays the SEM images of $\mathrm{ZnSnS}_{3}$ and N/S-rGO@ $\mathrm{ZnSnS}_{3}$ electrodes after 50 cycles at $0.1 \mathrm{~A} \mathrm{~g}^{-1}$. As expected, a legible crack emerges from $\mathrm{ZnSnS}_{3}$ electrode and the pristine morphology of $\mathrm{ZnSnS}_{3}$ cubes disappears completely (Fig. S5b) in comparison to the as-prepared electrode (Fig. S5a), resulting from the repeated volume expansion/contraction during cycling. Meanwhile, the significant agglomeration of the active particle scattered on the whole electrode lowers the electrochemical activity (Fig. S5c), which partly explains the poor electrochemical properties of $\mathrm{ZnSnS}_{3}$ anode. On the contrary, the morphology of N/S-rGO encapsulated $\mathrm{ZnSnS}_{3}$ cubes is well retained (Fig. S5d, e and f), and thus the structural advantages of $\mathrm{N} / \mathrm{S}-\mathrm{rGO} @ \mathrm{ZnSnS}_{3}$ is sustainable during cycling. The results convincingly illuminate that $\mathrm{ZnSnS}_{3}$ encapsulated by $\mathrm{N} / \mathrm{S}$-rGO brings a superior rate capability and cycling stability to $\mathrm{Na}^{+}$storage. As shown in Fig. 4, the performance improvement of N/S-rGO@ $\mathrm{ZnSnS}_{3}$ anode rooted in its structure and composition can be 


\section{ACCEPTED MANUSCRIPT}

ascribed to five factors as follows: (i) the self-matrix and self-conductivity properties due to the step-by-step alloying/dealloying processes ${ }^{[14,17,33,43]}$; (ii) the enhanced strain tolerability and shortened diffusion paths for $\mathrm{Na}^{+}$benefitting from the hollow structure of $\mathrm{ZnSnS}_{3}{ }^{[16,25,26,44]}$; (iii) the improved electronic conductivity and increased electroactive sites deriving from the rGO dual-doping with $\mathrm{N} / \mathrm{S}$ heteroatoms ${ }^{[31,32,37,38]}$; (iv) the reinforced structural stability resulting from the compact encapsulation of $\mathrm{ZnSnS}_{3}$ by $\mathrm{rGO}$ with $\mathrm{N} / \mathrm{S}$ dual doping ${ }^{[19,30,37]}$; (v) the significantly improved reaction kinetics (discussed later) ${ }^{[8,30]}$. It is worth mentioning that the N/S-rGO@ $\mathrm{ZnSnS}_{3}$ anode in this work exhibits a competitive specific capacity and cycling stability compared with the other existing metal-chalcogenide based electrode materials (Table S1).

Electrochemical impedance spectroscopy (EIS) measurement is conducted to investigate reaction kinetics of the anode materials. Fig. 5a and b show the Nyquist plots of the $\mathrm{ZnSnS}_{3}$ and N/S-rGO@ $\mathrm{ZnSnS}_{3}$ electrodes at the different full-discharged state. Each plot consists of a sloping line in the low frequency region and one or two compressed semicircles in the high-to-medium frequency region. Given the generation of SEI resulting from the reduction of organic liquid electrolyte in the experimental system, the equivalent circuit composed of two RC parallel components is employed to fit the results of Nyquist plots (the inset of Fig. $5 b)^{[30,45]}$. In the equivalent circuits, $R_{s}$ stands for the ohmic resistance of the reaction system; the two parallel components respectively relate to the interface of SEI film $\left(\mathrm{R}_{\mathrm{sf}}\right.$ and $\left.C P E_{\mathrm{sf}}\right)$ and the charge transfer process $\left(\mathrm{R}_{\mathrm{ct}}\right.$ and $\left.\mathrm{CPE}_{\mathrm{ct}}\right)$ as well as the Warburg impedance $(\mathrm{W})$ related to the solid state diffusion of $\mathrm{Na}^{+[30,46]}$. The typical fitting result of $\mathrm{ZnSnS}_{3}$ electrode initially discharged 


\section{ACCEPTED MANUSCRIPT}

to $0.01 \mathrm{~V}$ is illustrated in Fig. S5a, and the relevant fitting parameters are presented in

Table S2. Notably the fitting numerical error is normally lower than $1 \%$, supporting the dependability of the equivalent circuit. The fitted values of $R_{\text {sf }}$ and $R_{c t}$ of the test electrodes are summarized in Fig. 5c. Evidently, $\mathrm{ZnSnS}_{3}$ electrode exhibits a visible soar in $\mathrm{R}_{\mathrm{sf}}\left(\mathrm{R}_{\mathrm{ct}}\right)$ ranging from $38.28 \Omega(413.51 \Omega)$ in the $1^{\text {st }}$ cycle to $145.42 \Omega(2362.49 \Omega)$ in the $150^{\text {th }}$ cycle. Particularly, two compressed semicircles are emerged only after 10 cycles due to the significant interface changes caused by the fast growth of SEI film. For $\mathrm{ZnSnS}_{3}$, such significant increase of $\mathrm{R}_{\mathrm{sf}}$ and $\mathrm{R}_{\mathrm{ct}}$ results in the rapid pulverization, fast capacity fading, poor rate capability, and reduced reactivity of the active material owing to the large volume fluctuation, potential agglomeration, and deteriorative electrical contact ${ }^{[30]}$. Compared with $\mathrm{ZnSnS}_{3}$, N/S-rGO@ $\mathrm{ZnSnS}_{3}$ electrode displays a smaller impedance with more stability. In particular, $R_{s f}\left(R_{c t}\right)$ is only changed from $31.29 \Omega(102.42 \Omega)$ in the $1^{\text {st }}$ cycle to $74.21 \Omega(301.37 \Omega)$ in the $150^{\text {th }}$ cycle, demonstrating the low polarization and relatively stable structure with the incorporation of N/S codoped $\mathrm{rGO}$ which partly explain the prominent rate capability and excellent cyclability.

According to the linear relationship between $Z^{\prime}$ versus $\omega^{-1 / 2}$ at low-frequency region (Fig. S6b and c) and the Equation 1 and 2, the $\mathrm{Na}^{+}$diffusion coefficients (D) in $\mathrm{ZnSnS}_{3}$ and N/S-rGO@ $\mathrm{ZnSnS}_{3}$ after different cycles are also determined ${ }^{[8,45-47]}$.

$D=R^{2} T^{2} / 2 A^{2} n^{4} F^{4} C^{2} \sigma_{w}{ }^{2}$

$Z^{\prime}=R_{s}+R_{c t}+\sigma_{w} \omega^{-1 / 2}$

Where R, T, A, n , F, C, $\sigma_{w}$ and $\omega$ are the gas constant, the absolute temperature, the 


\section{ACCEPTED MANUSCRIPT}

surface area of the anode, the number of electrons per molecule during cycling, the Faraday constant, the concentration of $\mathrm{Na}^{+}$in the electrolyte solution, the Warburg factor, and the angular frequency in the low frequency region, respectively. Estimated by Equation 1 and 2, the results in Fig. 5d distinctly illuminate that the $\mathrm{D}$ of N/S-rGO@ZnSnS $3\left(\mathrm{ZnSnS}_{3}\right)$ slightly increases from $6.28 \times 10^{-20}\left(8.55 \times 10^{-20}\right)$ in the $1^{\text {st }}$ cycle to $1.18 \times 10^{-19}\left(1.26 \times 10^{-19}\right)$ in the $2^{\text {nd }}$ cycle probably due to the irreversible transformation of $\mathrm{ZnSnS}_{3}$ during the initial cycle activation. After 5 cycles, it shows a downward trend for both electrodes, but the pristine $\mathrm{ZnSnS}_{3}$ electrode demonstrates more descending approach. The value of $\mathrm{D}$ for $\mathrm{N} / \mathrm{S}-\mathrm{rGO} @ \mathrm{ZnSnS}_{3}$ is approximately two to fifteen times larger than that of $\mathrm{ZnSnS}_{3}$. It indicates that the ionic transport kinetics and electrochemical activity of $\mathrm{ZnSnS}_{3}$ nano-microcubes are greatly enhanced by the encapsulating of $\mathrm{rGO}$ with $\mathrm{N} / \mathrm{S}$ codoped $^{[19,30]}$. Therefore, it is believed that N/S-rGO@ $\mathrm{ZnSnS}_{3}$ is a promising high-performance anode material for the high energy/power densities SIBs.

\subsection{Electrochemical reaction mechanism}

To reveal the sodiation/desodiation behaviors of hollow $\mathrm{ZnSnS}_{3}$ nano-microcubes served as SIBs anode, in situ XRD is performed to trace structural evolution. Fig. 6a exhibits the typical XRD patterns of test electrode charged/discharged at potentials between 0.01 and $3.0 \mathrm{~V}$ with a current density of $50 \mathrm{~mA} \mathrm{~g}^{-1}$. It may be pointed out that the peaks located at $38.6^{\circ}, 41.1^{\circ}$ and $43.9^{\circ}$ are attributed to the $\mathrm{BeO}$ (JCPDS Card no. $35-0818$ ), and the sharp peaks centered at $46.0^{\circ}$ and $50.5^{\circ}$ are ascribed to the Be (JCPDS 


\section{ACCEPTED MANUSCRIPT}

Card no. 22-0111) of the in situ reaction cell ${ }^{[42,46,48]}$. The reaction mechanism of $\mathrm{ZnSnS}_{3}$ anode is divided into five stages ( $\left.\mathrm{S} 1, \mathrm{~S} 2, \mathrm{~S} 3, \mathrm{~S} 4, \mathrm{~S} 5\right)$ as shown in Fig. 6b. In stage 1, when the discharge voltage reaches from open circuit voltage (OCV) to $0.91 \mathrm{~V}$, the two main peaks located at $26.2^{\circ}$ and $33.7^{\circ}$ as well as the peak at $37.6^{\circ}$ of $\mathrm{ZnSnS}_{3}$ shift towards a lower $2 \theta$ value and gradually weaken in intensity. Meanwhile, another peak at $51.5^{\circ}$ disappears completely, suggesting the lattice expansion due to the occurrence of $\mathrm{Na}^{+}$intercalation into $\mathrm{ZnSnS}_{3}{ }^{[22,49,50]}$, which can be expressed as Equation 3. As the following discharge voltage drops down to $0.45 \mathrm{~V}$ in stage 2, the main peak of $\mathrm{ZnSnS}_{3}$ continues to shift toward a lower $2 \theta$ and the peak intensities move downward. In particular, the peak at $37.6^{\circ}$ almost disappears, which is principally perceived to be the conversion of $\mathrm{Na}_{x} \mathrm{ZnSnS}_{3}$ into $\mathrm{Na}_{y} \mathrm{ZnS}_{3}$ and $\mathrm{Na}_{y} \mathrm{SnS}_{3}$, caused by the further sodiation (Equation 4). Such a dynamic change suggests that the conversion of $\mathrm{Na}_{x} \mathrm{ZnSnS}_{3}$ may not trigger the direct generation of elemental $\mathrm{Zn}$ and $\mathrm{Sn}$. In stage 3, along with the discharge voltage of $0.01 \mathrm{~V}$, the two main peaks of the electrode move towards a lower angle and become gradually weakened in intensity until complete disappearance, implying that $\mathrm{Na}_{y} \mathrm{ZnS}_{3}$ and $\mathrm{Na}_{y} \mathrm{SnS}_{3}$ are fully transformed into $\mathrm{Na}_{z} \mathrm{Zn}$ and $\mathrm{Na}_{z} \mathrm{Sn}$, corresponding to the reactions of Equation 5 and 6, respectively. Due to the lack of prominent peaks related to the $\mathrm{Na}_{z} \mathrm{Zn}$ and $\mathrm{Na}_{z} \mathrm{Sn}$, it can be speculated that they have an amorphous structure or their contents in the electrode are negligible that cannot be detected in the XRD pattern ${ }^{[21,51]}$. Conversely, as the desodiation process continues, during charging back to $0.80 \mathrm{~V}$, a new pair of peaks emerge with increasing intensity, implying that the inverse alloying reactions mainly occur in stage 4. Furthermore, after 


\section{ACCEPTED MANUSCRIPT}

fully charged to $3.0 \mathrm{~V}$ in stage 5 , the new pair of peaks located at $26.1^{\circ}$ and $33.5^{\circ}$ show the enhanced intensity, which can be assigned to zinc sulfide (JCPDS Card no. 89-2158) and tin sulfide (JCPDS Card no. 30-1377), indicating the occurrence of conversion process as explicated by Equation 7 and 8 .

Based on the in situ XRD results, the proposed structural evolution is in a good agreement with the CV curves and charge/discharge profiles illustrated earlier. Indeed, the sodium storage mechanisms of $\mathrm{ZnSnS}_{3}$ in the voltage range of $0.01 \sim 3.0 \mathrm{~V}$ are demonstrated as follows:

Initial discharge process:

$$
\begin{aligned}
& \mathrm{ZnSnS}_{3}+x \mathrm{Na}^{+}+x \mathrm{e}^{-} \rightarrow \mathrm{Na}_{x} \mathrm{ZnSnS}_{3} \\
& \mathrm{Na}_{x} \mathrm{ZnSnS}_{3}+x \mathrm{Na}^{+}+x \mathrm{e}^{-} \rightarrow \mathrm{Na}_{y} \mathrm{ZnS}_{3}+\mathrm{Na}_{y} \mathrm{SnS}_{3}+\mathrm{Na}_{2} \mathrm{~S} \\
& \mathrm{Na}_{y} \mathrm{ZnS}_{3}+x \mathrm{Na}^{+}+x \mathrm{e}^{-} \rightarrow \mathrm{Na}_{z} \mathrm{Zn}+\mathrm{Na}_{2} \mathrm{~S} \\
& \mathrm{Na}_{y} \mathrm{SnS}_{3}+x \mathrm{Na}^{+}+x \mathrm{e}^{-} \rightarrow \mathrm{Na}_{z} \mathrm{Sn}+\mathrm{Na}_{2} \mathrm{~S}
\end{aligned}
$$

Charge process:

$$
\begin{aligned}
& \mathrm{Na}_{z} \mathrm{Zn}+\mathrm{Na}_{2} \mathrm{~S} \rightarrow \mathrm{Na}^{+}+\mathrm{e}^{-}+\mathrm{ZnS}_{x} \\
& \mathrm{Na}_{z} \mathrm{Sn}+\mathrm{Na}_{2} \mathrm{~S} \rightarrow \mathrm{Na}^{+}+\mathrm{e}^{-}+\mathrm{SnS}_{x}
\end{aligned}
$$

Ex situ XPS analysis is conducted to further confirm the above reaction mechanisms from a structural evolution point of view. Fig. 7 shows $\mathrm{Zn} 2 \mathrm{p}$, Sn $3 \mathrm{~d}$ and $\mathrm{S} 2 \mathrm{p}$ XPS spectra of $\mathrm{ZnSnS}_{3}$ nano-microcubes at different states of charge between 0.01 and $3.0 \mathrm{~V}$. Compared with the initial state (Fig. 7a), when the discharge voltage reaches to $0.01 \mathrm{~V}$ (Fig. 7b), Zn 2p spectrum presents a lower binding energy shift, indicating the reduction process of $\mathrm{Zn}^{2+}$ to $\mathrm{Zn}^{0}$. Sn spectrum exhibits the similar trend with more complex shift, 
attributed to the valence state transformation from $\mathrm{Sn}^{4+}$ to $\mathrm{Sn}^{2+}$ and $\mathrm{Sn}^{0}$. The signals of $\mathrm{Zn}^{0}$ and $\mathrm{Sn}^{0}$ demonstrate the formation of metallic specimen, which are in good agreement with the results reported by Choi's group ${ }^{[52]}$ and Baggetto's group ${ }^{[53]}$. Moreover, the binding energy shifting toward a lower value is observed in the $\mathrm{S}$ spectrum, which is ascribed to the formation of $\mathrm{Na}_{2} \mathrm{~S}$ during sodiation process. The presence of $\mathrm{Na}_{2} \mathrm{~S}$ is also proved by the conspicuous $\mathrm{Na}$ 1s peaks shown in Fig. S5d. It is worthy to mention that the peak of sulfate/sulfite at about $168.1 \mathrm{eV}$ is obtained in the $\mathrm{S}$ spectrum, which can be assigned to the oxidation of $\mathrm{Na}_{2} \mathrm{~S}$ due to the extremely short exposure in air during the transportation of sample from vacuum box to XPS equipment $^{[54]}$. Expectedly, during charging back to $3.0 \mathrm{~V}$ (Fig. 7c), Zn and Sn are oxidized to a high valence state again during desodiation process. Thus, as a convictive supplement, the results of ex situ XPS indeed support the proposed reaction mechanisms deriving from in situ XRD analysis.

\section{Conclusions}

In this study, for the first time, a facile ingenious two-step strategy was successfully designed to integrate hollow $\mathrm{ZnSnS}_{3}$ nano-microcubes and N/S-rGO. The encapsulating of rGO doped with $\mathrm{N} / \mathrm{S}$ heteroatoms significantly influences the sodium storage of hollow $\mathrm{ZnSnS}_{3}$ nano-microcubes due to the simultaneous improvements in structural stability, electronic conductivity, electrochemical activity, and reaction kinetics. The resultant N/S-rGO@ $\mathrm{ZnSnS}_{3}$ anode can deliver a high discharge capacity 


\section{ACCEPTED MANUSCRIPT}

of $501.7 \mathrm{mAh} \mathrm{g}^{-1}$ after 100 cycles at $0.1 \mathrm{~A} \mathrm{~g}^{-1}$ with high Coulombic efficiency close to $100 \%$, and a reversible capacity of $290.7 \mathrm{mAh} \mathrm{g}^{-1}$ after 500 cycles at $1.0 \mathrm{~A} \mathrm{~g}^{-1}$ with capacity fading of $0.06 \%$ per cycle in the potential range between $0.01 \mathrm{~V}$ and $3.0 \mathrm{~V}$ (vs. $\left.\mathrm{Na} / \mathrm{Na}^{+}\right)$. The cycling stability as well as rate capability of $\mathrm{N} / \mathrm{S}-\mathrm{rGO} @ \mathrm{ZnSnS} \mathrm{S}_{3}$ are superior to those of the pristine hollow $\mathrm{ZnSnS}_{3}$ cubes and un-doped rGO composite. Furthermore, the sodium storage mechanism of the bimetallic sulfide hollow $\mathrm{ZnSnS}_{3}$ nano-microcubes is revealed by in situ XRD analysis combined with ex situ XPS observations. As a result, it is expected that our strategies can open an opportunity for the design of active materials in lithium/sodium ion batteries.

\section{Acknowledgements}

This work was financially supported by the National Natural Science Foundation of China (51572194), the Key Project of the Tianjin Science \& Technology Support Program (17YFZCGX00550), the Tianjin Major Program of New Materials Science and Technology (16ZXCLGX00070), and the National Key Research and Development Program of China (2018YFB0105900).

References

[1] J. Y. Hwang, S. T. Myung, Y. K. Sun, Chem. Soc. Rev. 46 (2017) 3529-3614.

[2] S. P. Ong, V. L. Chevrier, G. Hautier, A. Jain, C. Moore, S. Kim, X. H. Ma, G. 


\section{ACCEPTED MANUSCRIPT}

Ceder, Energy Environ. Sci. 4 (2011) 3680-3688.

[3] Y. Liang, W. H. Lai, Z. Miao, S. L. Chou, Small 14 (2018) 1702514-1702533.

[4] M. H. Han, E. Gonzalo, G. Singh, T. Rojo, Energy Environ. Sci. 8 (2015) 81-102.

[5] J. Lu, Z. W. Chen, F. Pan, Y. Cui, K. Amine, Electreochem. Energy Rev. 1 (2018) $35-53$.

[6] Y. Liu, X. Wang, X. Song, Y. Dong, L. Yang, L. Wang, D. Jia, Z. Zhao, J. Qiu, Carbon 109 (2016) 461-471.

[7] Q. Tang, Y. Cui, J. Wu, D. Qu, A. P. Baker, Y. Ma, X. Song, Y. Liu, Nano Energy 41 (2017) 377-386.

[8] L. L. Fan, X. F. Li, B. Yan, J. M. Feng, D. B. Xiong, D. J. Li, L. Gu, Y. R. Wen, S. Lawes, X. L. Sun, Adv. Energy Mater. 6 (2016) 1502057-1502069.

[9] Y. Xiao, J. Y. Hwang, I. Belharouak, Y. K. Sun, Nano Energy 32 (2017) 320-328.

[10] G. H. Newman, L. P. Klemann, J. Electrochem. Soc. 127 (1980) 2097-2099.

[11] Y. Jiang, M. Wei, J. K. Feng, Y. C. Ma, S. L. Xiong, Energy Environ. Sci. 9 (2016) $1430-1438$.

[12] X. Q. Xie, Z. M. Ao, D. W. Su, J. Q. Zhang, G. X. Wang, Adv. Funct. Mater. 25 (2015) 1393-1403.

[13] X. Liu, K. Zhang, K. X. Lei, F. J. Li, Z. L. Tao, J. Chen, Nano Res. 9 (2016) 198-206.

[14] Y. W. Denis, P. V. Prikhodchenko, C. W. Mason, S. K. Batabyal, J. Gun, S. Sladkevich, A. G. Medvedev, O. Lev, Nat. Commun. 4 (2013) 2922.

[15] J. Chen, S. Li, V. Kumar, P. S. Lee, Adv. Energy Mater. 7 (2017) 


\section{ACCEPTED MANUSCRIPT}

$1700180-1700187$.

[16] X. Cao, C. Tan, M. Sindoro, H. Zhang, Chem. Soc. Rev. 46 (2017) 2660-2677.

[17] X. F. Li, C. L. Wang, RSC Adv. 2 (2012) 6150-6154.

[18] X. Y. Yu, X. W. Lou, Adv. Energy Mater. 8 (2018) 1701592-1701628.

[19] Q. Guo, Y. Ma, T. Chen, Q. Xia, M. Yang, H. Xia, Y. Yu, ACS Nano 11 (2017) 12658-12667.

[20] Z. 1. Chen, R. B. Wu, M. Liu, H. Wang, H. B. Xu, Y. H. Guo, F. Fang, X. B. Yu, D. L. Sun, Adv. Funct. Mater. 27 (2017) 1702046-1702058.

[21] S. H. Dong, C. X. Li, X. L. Ge, Z. Q. Li, X. G. Miao, L.W. Yin, ACS Nano 11 (2017) 6474-6482.

[22] G. Z. Fang, Z. X. Wu, J. Zhou, C. Y. Zhu, X. X. Cao, T. Q. Lin, Y. M. Chen, C. Wang, A. Q. Pan, S. Q. Liang, Adv. Energy Mater. 8 (2018) 1703155-1703164.

[23] Y. Y. Wang, W. P. Kang, D. W. Cao, M. H. Zhang, Z. X. Kang, Z. Y. Xiao, R. M. Wang, D. F. Sun, J. Mater. Chem. A 6 (2018) 4776-4782.

[24] Y. M. Lin, Z. Z. Qiu, D. Z. Li, S. Ullah, Y. Hai, H. L. Xin, W. D. Liao, B. Yang, H. S. Fan, J. Xu, C. Z. Zhu, Energy Storage Mater. 11 (2018) 67-74.

[25] X. Rui, H. Tan, Q. Yan, Nanoscale 6 (2014) 9889-9924.

[26] X. Y. Yu, L. Yu, X. W. Lou, Adv. Energy Mater. 6 (2016) 1501333-1501347.

[27] H. Kang, Y. Liu, K. Cao, Y. Zhao, L. Jiao, Y. Wang, H. Yuan, J. Mater. Chem. A 3 (2015) 17899-17913.

[28] L. Li, S. Peng, H. B. Wu, L. Yu, S. Madhavi, X. W. Lou, Adv. Energy Mater. 5 (2015) 1500753-1500760. 


\section{ACCEPTED MANUSCRIPT}

[29] Z. Che, Y. Li, K. Chen, M. Wei, J. Power Sources 331 (2016) 50-57.

[30] B. Yan, X. Li, Z. Bai, L. Lin, G. Chen, X. Song, D. Xiong, D. Li, X. Sun, J. Mater. Chem. A 5 (2017) 4850-4860.

[31] P. Zheng, Z. Dai, Y. Zhang, K. N. Dinh, Y. Zheng, H. Fan, J. Yang, R. Dangol, B. Li, Y. Zong, Q. Yan, X. Liu, Nanoscale 9 (2017) 14820-14825.

[32] Z. Tian, J. Li, G. Zhu, J. Lu, Y. Wang, Z. Shi, C. Xu, Phys. Chem. Chem. Phys. 18 (2016) 1125-1130.

[33] Z. Zhang, Z. Li, L. Yin, New J. Chem. 42 (2018) 1467-1476.

[34] K. Chang, D. Geng, X. Li, J. Yang, Y. Tang, M. Cai, R. Li, X. Sun, Adv. Energy Mater. 3 (2013) 839-844.

[35] D. H. Youn, S. K. Stauffer, P. Xiao, H. Park, Y. Nam, A. Dolocan, G. Henkelman, A. Heller, C. B. Mullins, ACS Nano 10 (2016) 10778-10788.

[36] Z. Zhang, X. Shi, X. Yang, Y. Fu, K. Zhang, Y. Lai, J. Li, ACS Appl. Mater. Interfaces 8 (2016) 13849-13856.

[37] L. Fan, X. Li, X. Song, N. Hu, D. Xiong, A. Koo, X. Sun, ACS Appl. Mater. Interfaces 10 (2018) 2637-2648.

[38] H. Shan, X. Li, Y. Cui, D. Xiong, B. Yan, D. Li, A. Lushington, X. Sun, Electrochim. Acta 205 (2016) 188-197.

[39] X. Li, Y. Hu, J. Liu, A. Lushington, R. Li, X. Sun, Nanoscale 5 (2013) 12607-12615.

[40] L. Yu, L. Zhang, H. B. Wu, X. W. Lou, Angew. Chem. 126 (2014) 3711-3714.

[41] H. Cao, X. Qian, C. Wang, X. Ma, J. Yin, Z. Zhu, J. Am. Chem. Soc. 127 (2005) 


\section{ACCEPTED MANUSCRIPT}

16024-16025.

[42] X. Ou, C. Yang, X. Xiong, F. Zheng, Q. Pan, C. Jin, M. Liu, K. Huang, Adv. Funct. Mater. 27 (2017) 1606242-1606251.

[43] T. Y. Wang, D. W. Su, D. Shanmukaraj, T. Rojo, M. Armand, G. X. Wang, Electreochem. Energy Rev. 1 (2018) 200-237.

[44] Y. J. Fang, L. F. Xiao, Z. X. Chen, X. P. Ai, Y. L. Cao, H. X. Yang, Electreochem. Energy Rev. 1 (2018) 294-323.

[45] Y. Li, Y. Zheng, J. Yao, J. Xiao, J. Yang, S. Xiao, RSC Adv. 7 (2017) 31287-31297.

[46] X. Ou, J. Li, F. Zheng, P. Wu, Q. Pan, X. Xiong, C. Yang, M. Liu, J. Power Sources 343 (2017) 483-491.

[47] X. Cao, A. Pan, Y. Zhang, J. Li, Z. Luo, X. Yang, S. Liang, G. Cao, ACS Appl. Mater. Interfaces 8 (2016) 27632-27641.

[48] C. Yang, X. Ou, X. Xiong, F. Zheng, R. Hu, Y. Chen, M. Liu, K. Huang, Energy Environ. Sci. 10 (2017) 107-113.

[49] X. Ou, X. Xiong, F. Zheng, C. Yang, Z. Lin, R. Hu, C. Jin, Y. Chen, M. Liu, J. Power Sources 325 (2016) 410-416.

[50] S. S. Zhang, J. Mater. Chem. A 3 (2015) 7689-7694.

[51] M. Gu, A. Kushima, Y. Shao, J. G. Zhang, J. Liu, N. D. Browning, J. Li, C. Wang, Nano Lett. 13 (2013) 5203-5211.

[52] J. Y. Jang, Y. Lee, Y. Kim, J. Lee, S. M. Lee, K. T. Lee, N. S. Choi, J. Mater. Chem. A 3 (2015) 8332-8338.

[53] L. Baggetto, P. Ganesh, R. P. Meisner, R. R. Unocic, J. C. Jumas, C. A. Bridges, G. 


\section{ACCEPTED MANUSCRIPT}

M. Veith, J. Power Sources 234 (2013) 48-59.

[54] J. M. Chiu, T. C. Chou, D. P. Wong, Y. R. Lin, C. A. Shen, S. Hy, B. J. Hwang, Y.

Tai, H. L. Wu, L. C. Chen, K. H. Chen, Nano Energy 44 (2018) 438-446. 


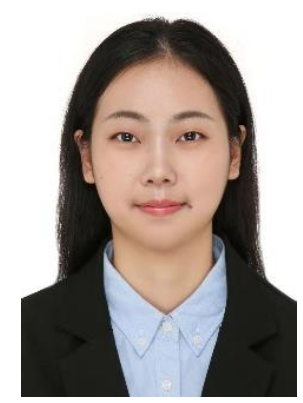

Xiaojing Liu is currently a M.S. in the School of Physics and Materials Science at Tianjin Normal University. She received her B.S. (2016) degree from the College of Chemistry and Chemical Engineering at Henan University (Kaifeng, China). Her current research interests focus on the controllable preparation of micro/nanostructures and their applications in lithium/sodium ion batteries and lithium-sulfur batteries.

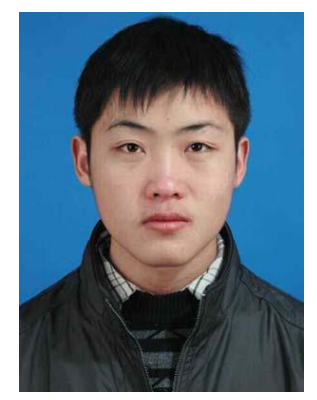

Youchen Hao is currently a Ph.D. candidate in the School of Materials Science and Technology at Xi'an University of Technology. He received his B.E. degree in the College of Physics and Materials Science, Tianjin Normal University in 2018. He received his B.D. degree in School of Chemical Engineering, Anhui University of Science and Technology in 2015. His research interests focus on nanomaterials for sodium ion batteries and lithium-sulfur batteries.

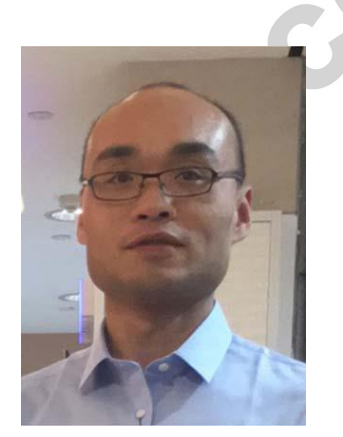

Jie Shu is currently an associate professor at Ningbo University. He received his Ph.D. degree in Condensed Matter Physics from Institute of Physics, Chinese Academy of Sciences in 2007. He ever worked as a postdoctoral researcher at National Institute of Advanced Industrial Science and Technology (Japan), Université de Picardie Jules Verne and Centre national de la recherché 


\section{ACCEPTED MANUSCRIPT}

scientifique (France) in 2007-2009. His research interest is focused on energy storage materials. He has published more than 100 papers, 2 book chapters, and 30 patents.

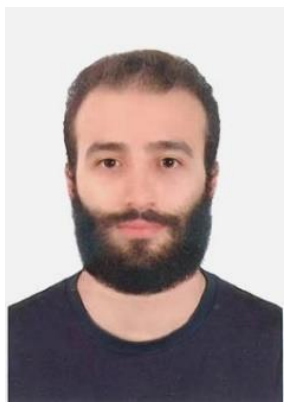

Hirbod Maleki Kheimeh Sari is currently a Ph.D. candidate in the Institute of Advanced Electrochemical Energy at Xi'an University of Technology. He received his Master's degree from the College of Mechanical Engineering, Malaysia University of Technology in 2014. His research interests primarily focus on the design and synthesis of novel nanomaterials for energy storage, especially cathode materials for lithium/sodium ion batteries.

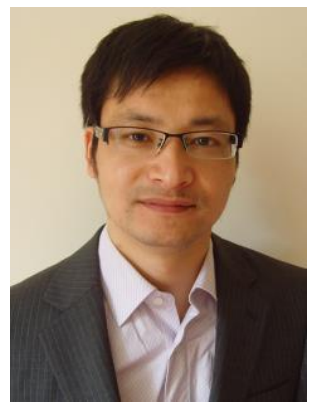

Dr. Liangxu Lin is currently a Vice-Chancellor Fellow at the University of Wollongong. He completed his $\mathrm{PhD}$ in Engineering Materials at The University of Sheffield at the end of 2013. After two postdoc periods at the University of Exeter, he joined Wuhan University of Science and Technology as a Professor. His research focuses on two-dimensional nanomaterials for electrochemical, catalysis and bio-science applications.

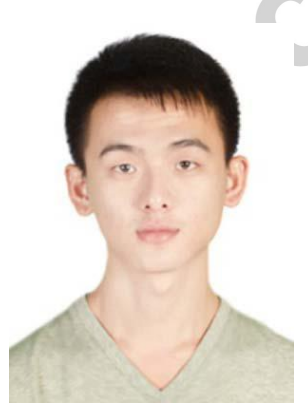

Huari Kou is currently a graduate student in the College of Physics and Materials Science, Tianjin Normal University. He received his BS degree from College of Science, Xi'an Jiaotong University in 2015. His research focus is on atomic layer deposition and sodium ion battery materials. 


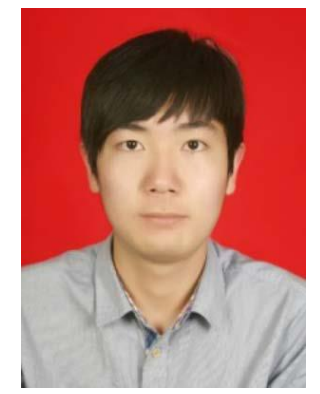

Jianwei Li received his B.D. degree in School of Physics and Materials Science, Ludong University in 2015. He is currently pursuing his M.S. degree at the College of Physics and Materials Science, Tianjin Normal University. His research interests focus on high performance electrode materials and their applications in supercapacitors and sodium ion batteries.

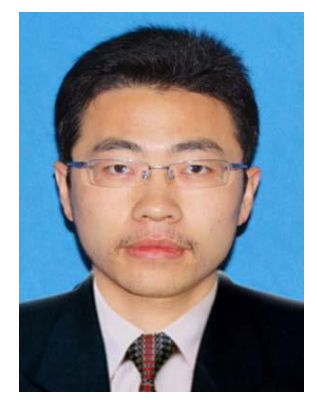

Wen Liu is currently a Ph.D. candidate in the School of Materials Science and Technology at Xi'an University of Technology. He received his B.E. degree in the College of Physics and Materials Science, Tianjin Normal University in 2018. He received his BS degree from College of Chemistry and Materials Science, Shanxi normal University in 2015. His research focus is on the design and synthesis of novel nanomaterials for lithium and sodium ion batteries.

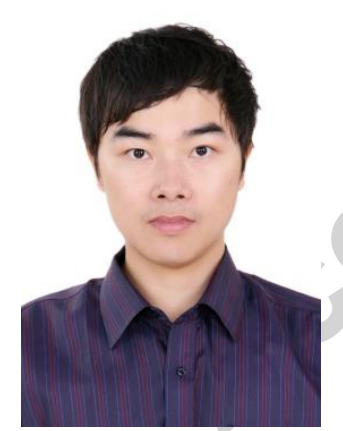

Bo Yan is currently an associate professor in the School of Materials Science and Technology at Xi' an University of Technology. He received his Ph.D. degree (2017) in the School of Materials Science and Technology at China University of Geosciences (Beijing). He received his M.E. (2014) and B.E. (2011) degree from the College of Chemistry and Bioengineering at Guilin University of Technology (Guilin, China). His current research interests focus on the controllable preparation of micro/nanostructures and their applications in lithium/sodium ion batteries and lithium-sulfur batteries. 


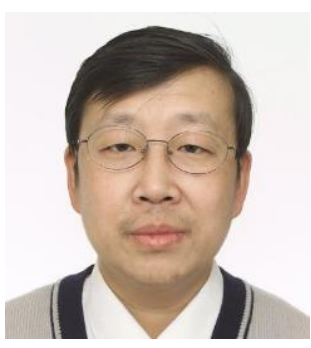

Dejun $\mathrm{Li}$ is currently a full professor at Tianjin Normal University. He obtained his Ph.D. at Tsinghua University in 1999. He then worked three years as a postdoctoral follow at Northwestern University of USA. Since 1999 he has been focusing on various thin films, coatings, and nano materials for protection, energy storage and conversion. His research group is currently working on design, synthesis, and applications of various coatings for surface modification of the electrodes of various high performance batteries and supercapacitors as well as tools. He has authored and co-authored over 150 refereed journal articles and 11 patents.

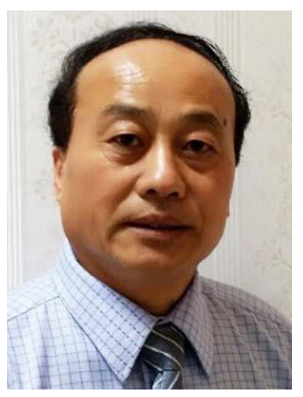

Jiujun Zhang is a Professor at Shanghai University. He is a Principal Research Officer (Emeritus) and Technical Core Competency Leader at the National Research Council of Canada Energy (NRC). Dr. Zhang received his BS and MSc in electrochemistry from Peking University in 1982 and 1985, respectively, and his $\mathrm{PhD}$ in electrochemistry from Wuhan University in 1988. Dr. Zhang has over 30 years of scientific research experience, particularly in the area of electrochemical energy storage and conversion. He is also the Adjunct Professor at the University of British Columbia and the University of Waterloo.

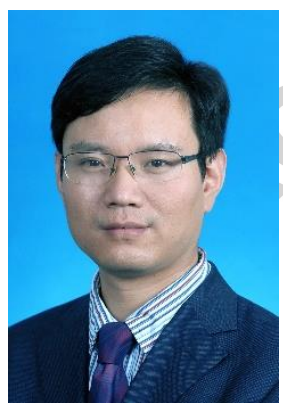

Xifei Li is currently a full professor at Tianjin Normal University and Xi'an University of Technology. Prof. Li's research group is currently working on design, synthesis as well as performance improvement of the anodes and the cathodes with various structures for high performance lithium ion batteries, lithium sulfur batteries, sodium ion batteries, and supercapacitors. He has authored and co-authored over 190 refereed journal articles with more than 7300 citations, two invited book chapters as well as 13 patents. 


\section{ACCEPTED MANUSCRIPT}

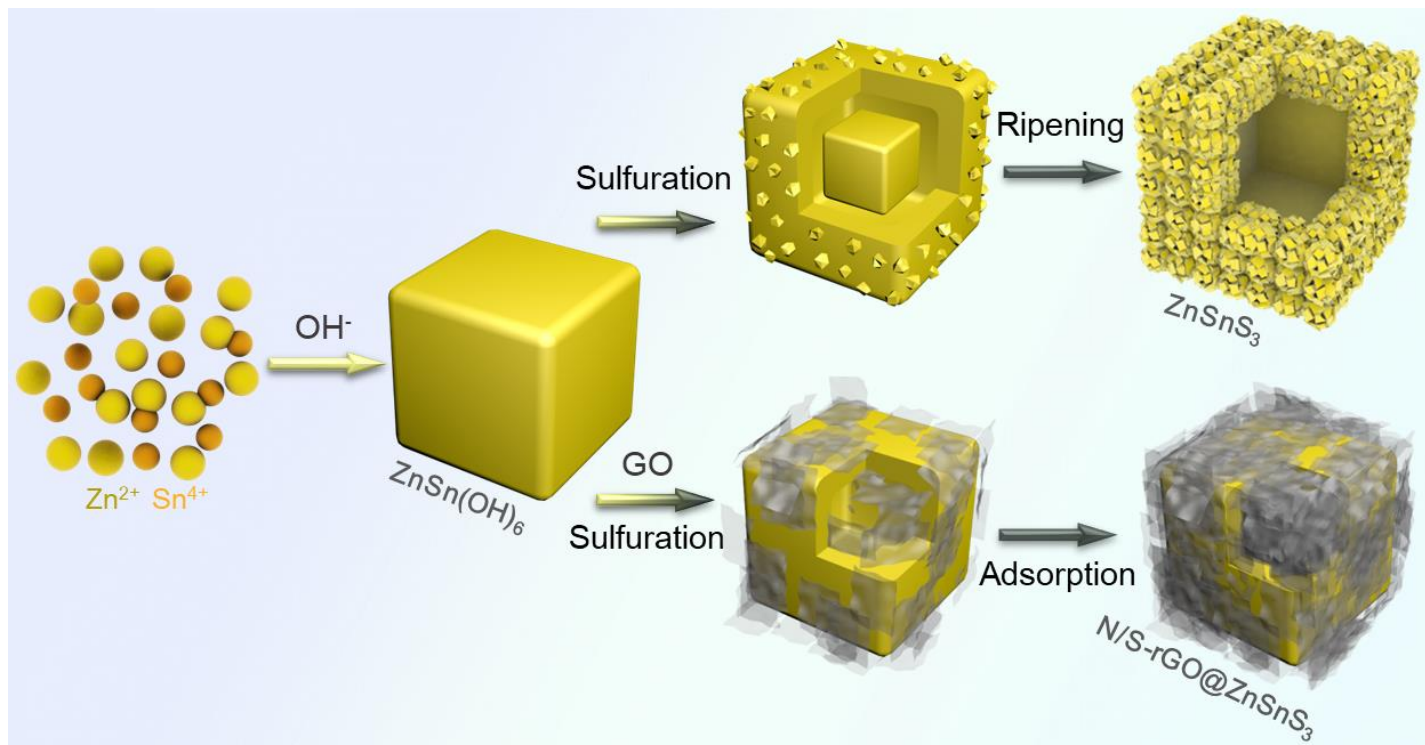

Scheme 1. Schematic illustration of the preparation processes of $\mathrm{ZnSnS}_{3}$ and N/S-rGO@ZnSnS 3. 


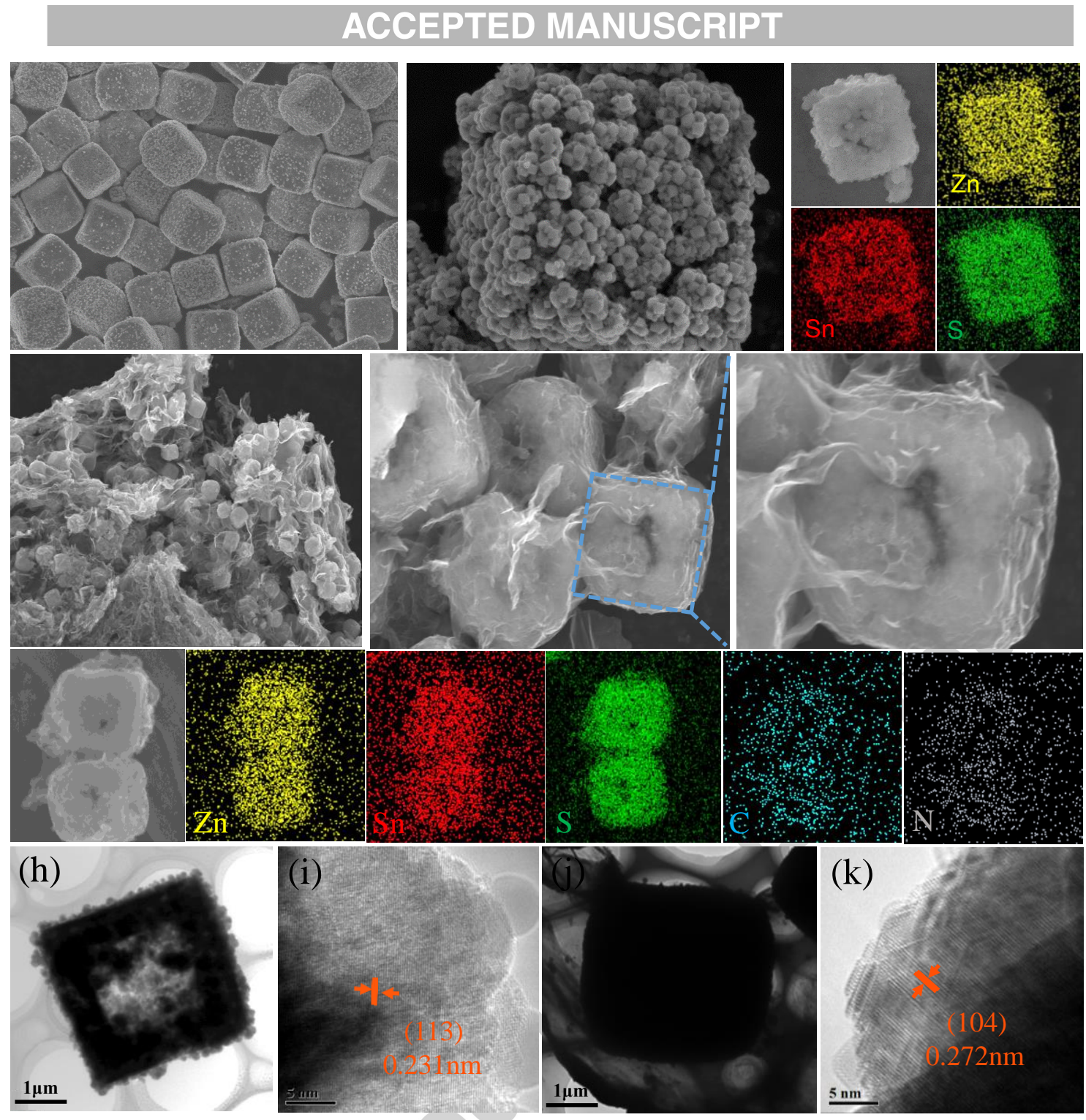

Fig. 1. FESEM images of $\mathrm{ZnSnS}_{3}$ prepared by the hydrothermal sulfidation of $\mathrm{ZnSn}(\mathrm{OH})_{6}$ for (a) $9 \mathrm{~h}$ and (b) $18 \mathrm{~h}$. (c) EDS mappings of desired $\mathrm{ZnSnS}_{3}$. (d-f) FESEM images of N/S-rGO@ZnSnS 3 . (g) EDS mappings of N/S-rGO@ZnSnS. (h) TEM and (i) high resolution TEM images of $\mathrm{ZnSnS}_{3}$. (j) TEM and (k) high resolution TEM images of N/S-rGO@ZnSnS 3 . 

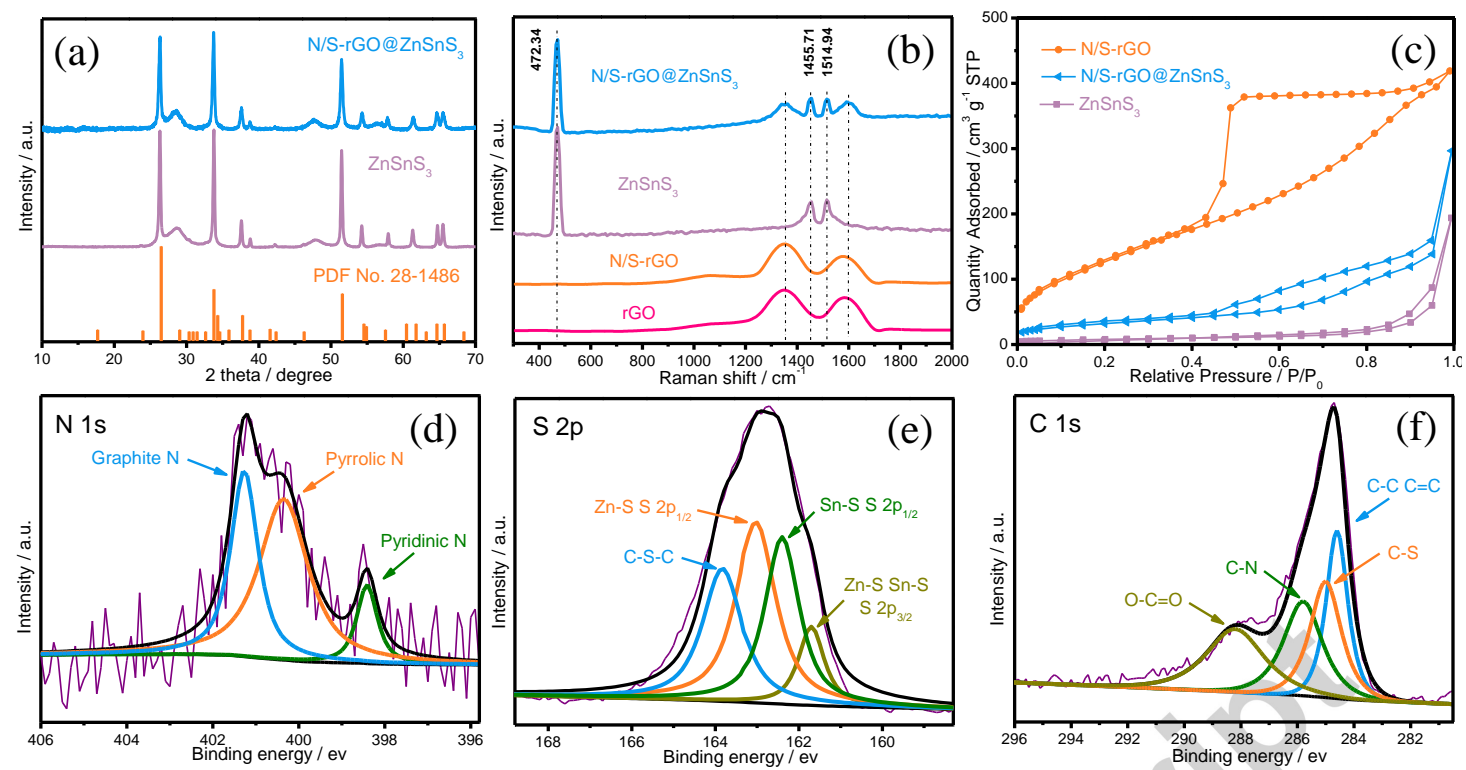

Fig. 2. (a) XRD patterns of $\mathrm{ZnSnS}_{3}$ and N/S-rGO@ $\mathrm{ZnSnS}_{3}$. (b) Raman spectra of rGO, N/S-rGO, $\mathrm{ZnSnS}_{3}$ and N/S-rGO@ $\mathrm{ZnSnS}_{3}$. (c) $\mathrm{N}_{2}$ adsorption/desorption isotherm curves of N/S-rGO, ZnSnS 3 , and N/S-rGO@ZnSnS 3 . XPS spectra of (d) N 1s, (e) S 2p and (f) C 1s for N/S-rGO@ $\mathrm{ZnSnS}_{3}$. 

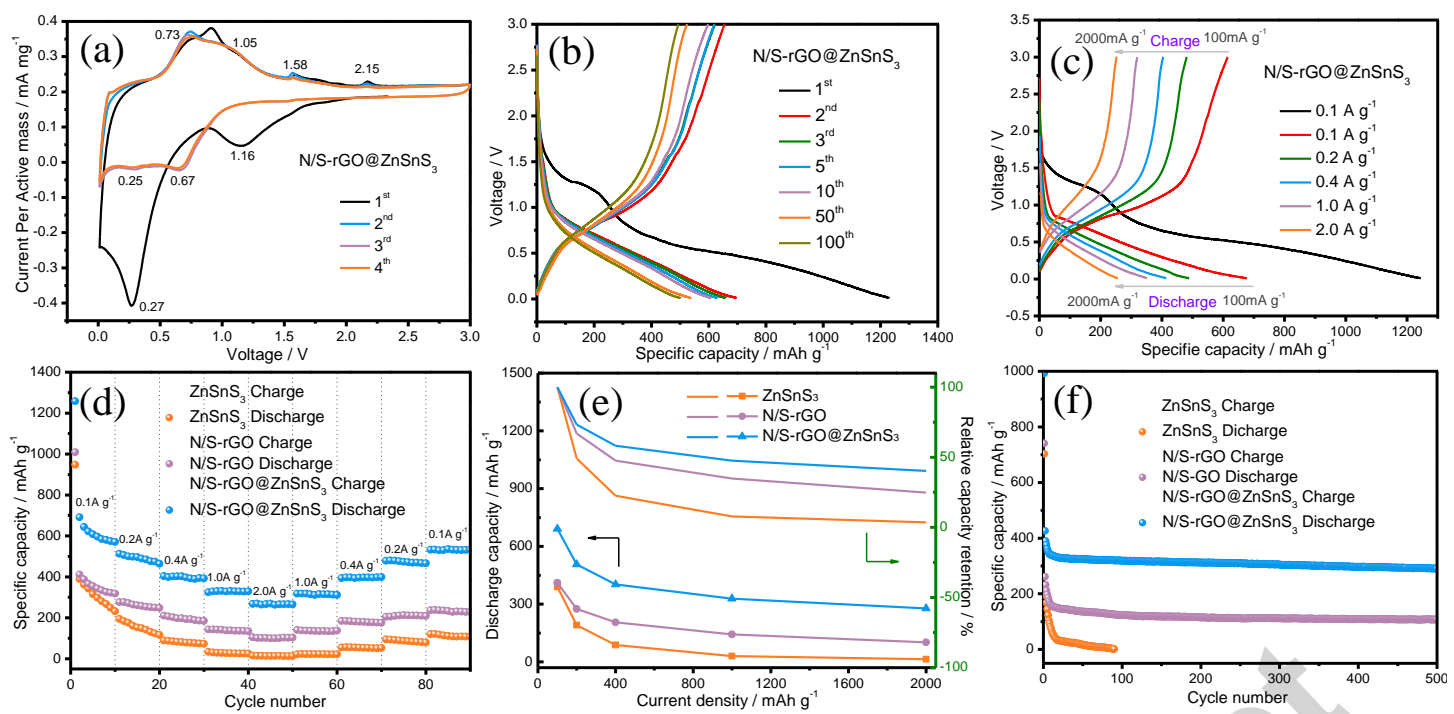

Fig. 3. (a) Cyclic voltammograms at a scanning rate of $0.1 \mathrm{mV} \mathrm{s}^{-1}$ and (b) charge-discharge curves at a current density of $0.1 \mathrm{~A} \mathrm{~g}^{-1}$ of the N/S-rGO@ $\mathrm{ZnSnS}_{3}$ anode. (c) Charge/discharge curves of the $\mathrm{N} / \mathrm{S}-\mathrm{rGO} @ \mathrm{ZnSnS}_{3}$ electrode at various current densities. (d) Rate cycling performance, (e) relative capacity retention at various current densities from 0.1 to $2.0 \mathrm{~A} \mathrm{~g}^{-1}$, and (f) long-term cycling performance at $1.0 \mathrm{~A} \mathrm{~g}^{-1}$ of N/S-rGO, ZnSnS 3 , and N/S-rGO@ $\mathrm{ZnSnS}_{3}$ electrodes. 


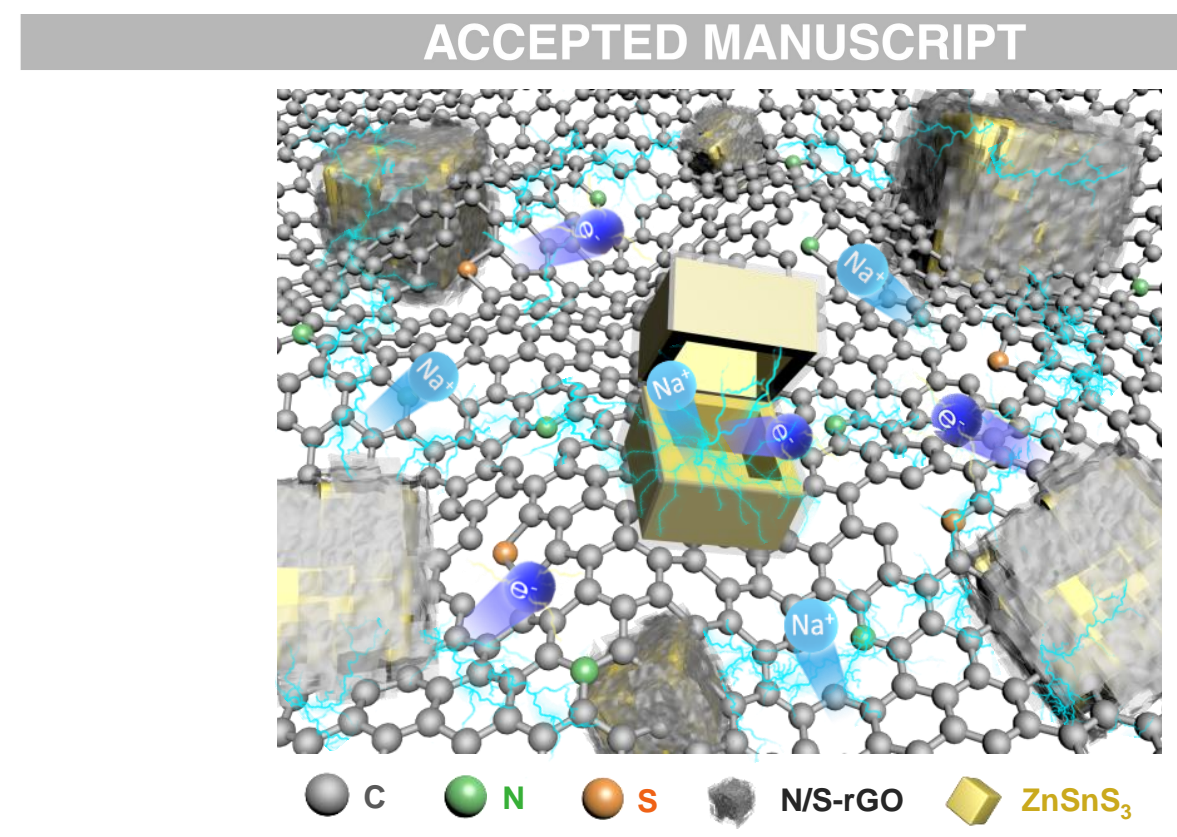

Fig. 4. Schematic diagram showing the structural advantages of $\mathrm{N} / \mathrm{S}-\mathrm{rGO} @ \mathrm{ZnSnS}_{3}$ in sodium storage. 

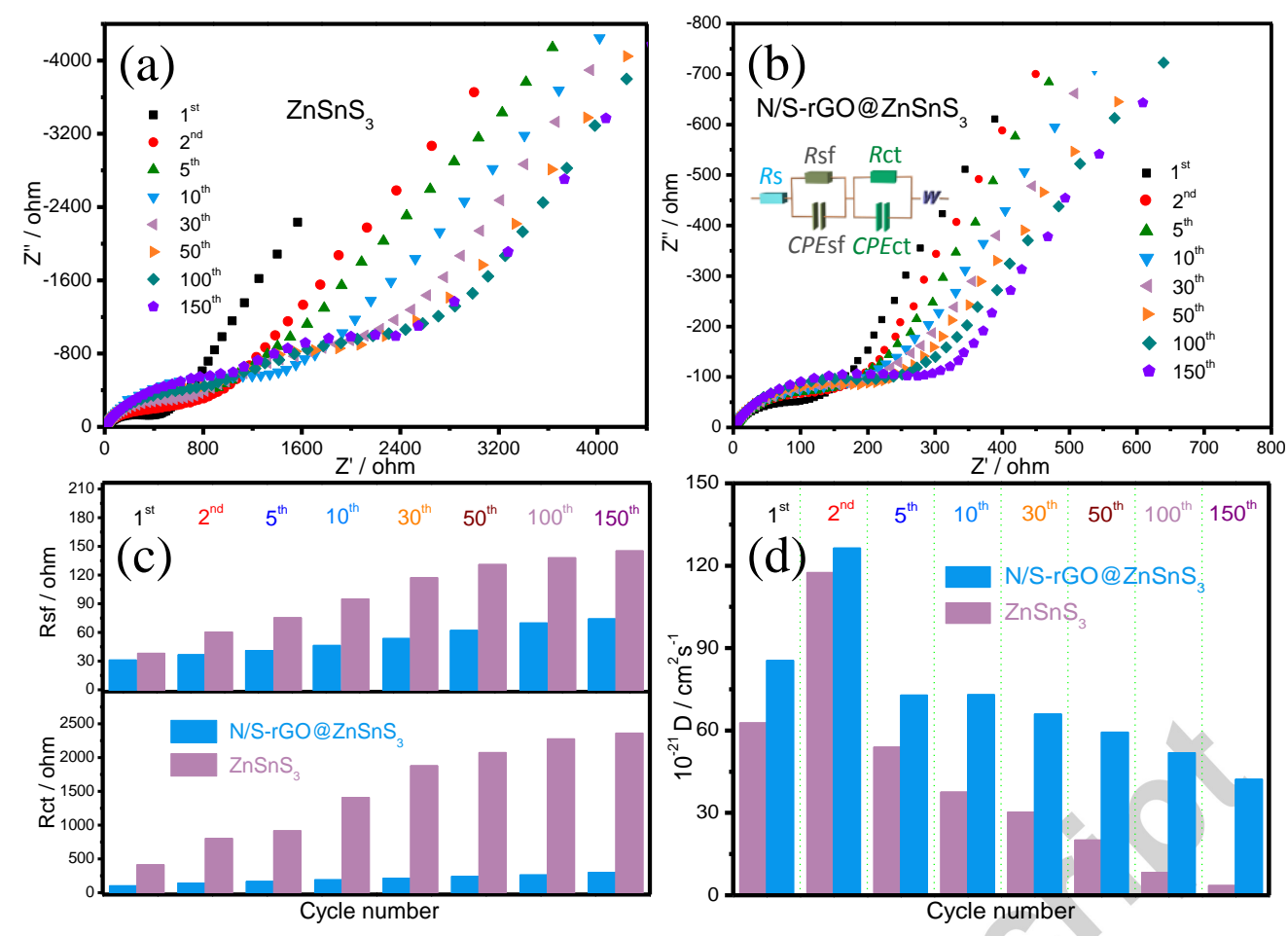

Fig. 5. Nyquist plots of (a) N/S-rGO@ $\mathrm{ZnSnS}_{3}$ (the equivalent circuits shown in the inset) and (b) $\mathrm{ZnSnS}_{3}$ electrodes at full-discharged state after various cycles. (c) EIS parameters of $\mathrm{N} / \mathrm{S}-\mathrm{rGO} @ \mathrm{ZnSnS}_{3}$ and $\mathrm{ZnSnS}_{3}$ electrodes derived from the equivalent circuit. (d) $\mathrm{Na}^{+}$diffusion coefficients of $\mathrm{N} / \mathrm{S}-\mathrm{rGO} @ \mathrm{ZnSnS}_{3}$ and $\mathrm{ZnSnS}_{3}$ after various discharge/charge cycles. 

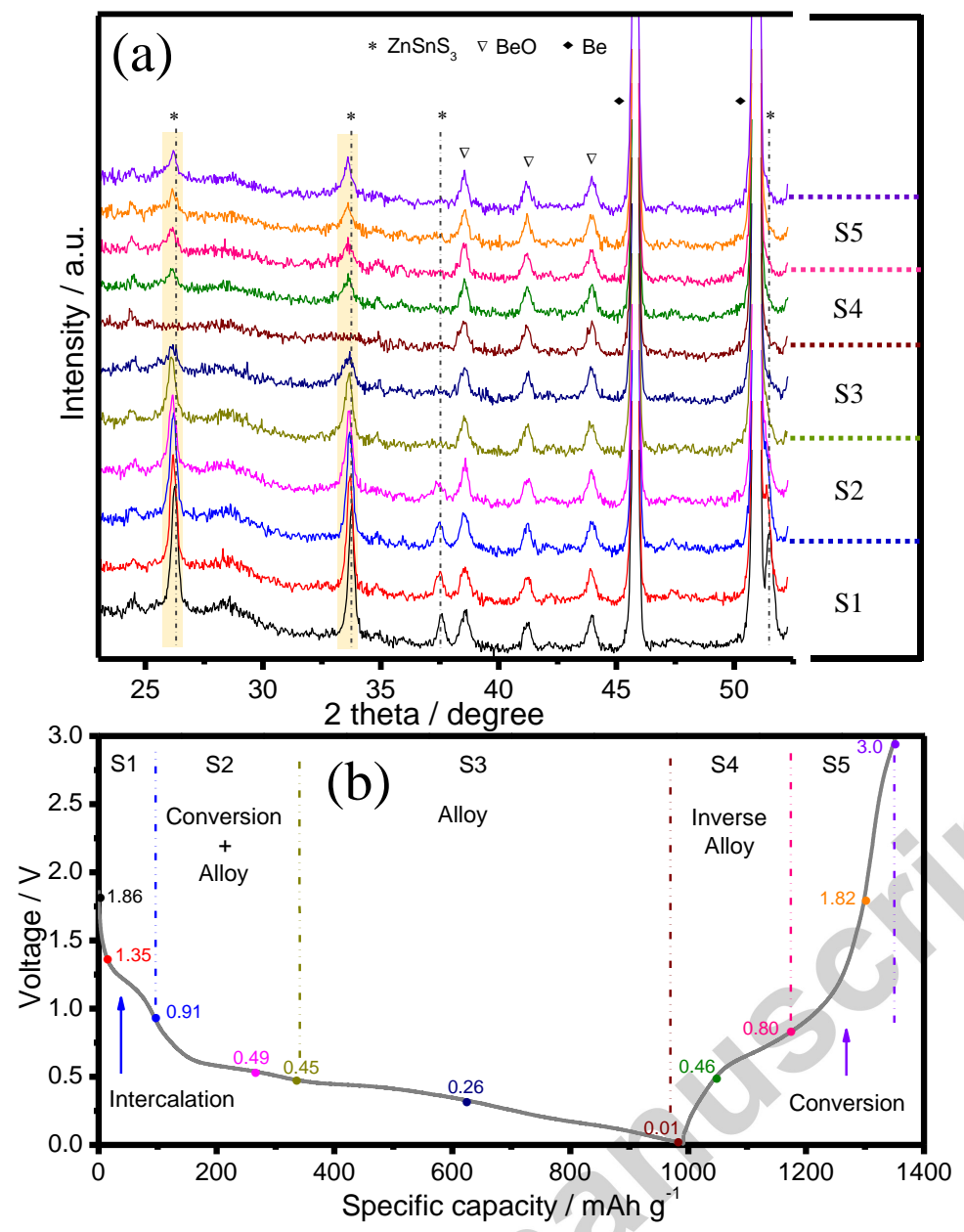

Fig. 6. (a) In situ XRD patterns collected during the first discharge/charge process of

$\mathrm{ZnSnS}_{3}$ electrode (b) at different stage in the voltage range of 0.01-3.0 V. 


\section{ACCEPTED MANUSCRIPT}
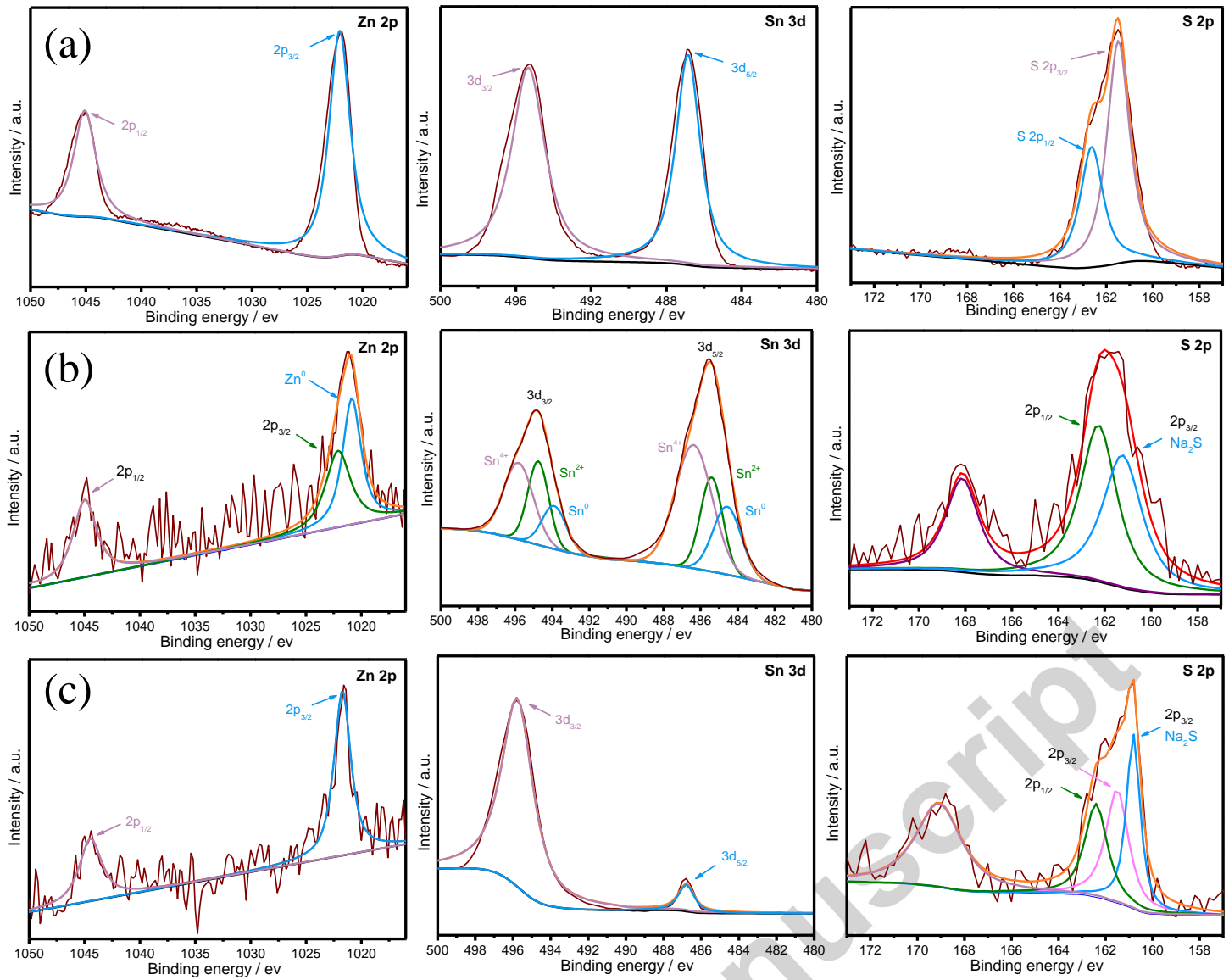

Fig. 7. Ex-situ XPS Zn 2p, Sn $3 d$ and S 2p spectra of (a) $\mathrm{ZnSnS}_{3}$; (b) sodiation and (c) desodiation of $\mathrm{ZnSnS}_{3}$ after the 1st cycle. 


\section{ACCEPTED MANUSCRIPT}

\section{Highlights}

$>$ N/S dual-doped rGO encapsulating hollow $\mathrm{ZnSnS}_{3}$ cubes are successfully fabricated.

$>$ The structural advantages and reaction kinetics of the resultant electrodes is revealed.

$>$ The desired electrode delivers superior cycling stability and rate capacity for Na-storage.

$>$ The structural evolutions of $\mathrm{ZnSnS}_{3}$ reaction with sodium are systematically studied. 